\title{
BEHAVIOUR OF IMPROVED DIRECT-WELDED CONNECTIONS IN SQUARE CFST COLUMN MOMENT FRAMES UNDER BIDIRECTIONAL LOADING
}

\author{
Helmy Tjahjanto ${ }^{1,2, *}$, Gregory MacRae ${ }^{2}$ and Anthony Abu ${ }^{2}$ \\ ${ }^{1}$ Department of Civil Engineering, Parahyangan Catholic University, Jl. Ciumbuleuit 94 Bandung 40141, Indonesia \\ ${ }^{2}$ Department of Civil and Natural Resources Engineering, University of Canterbury, Private Bag 4800 Christchurch 8140, New Zealand \\ * (Corresponding author.Ph.+62-22-2033-692, E-mail: helmy.hermawan@unpar.ac.id)
}

\section{A B S T RA C T}

The behaviour of square concrete-filled steel tubular (CFST) column subassemblies with direct-welded connections has been experimentally investigated. The connection strength and stiffness have been improved by utilizing through -rods and washer plates to the column. Bidirectional loading tests have been conducted and indicate that the direct-welded connections with through-rods and washer plates result in better performance compared to the unstiffened connection. Out-of-plane shear fracture in the column tube plates due to the high stress concentration at the beam flange tips is critical and may limit the capacity of the connections. Numerical analyses have been conducted to obtain the relationship between the considered design parameters and the stress concentration in the tube plates, which has subsequently been formulated for design. The elastic rotational stiffness of the CFST joints for moment frame analyses has also been developed.
ART ICLE HIS T ORY

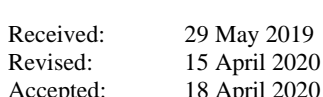

Accepted: $\quad 18$ April 2020

\section{K E Y W O R D S}

\section{Introduction}

Concrete-filled steel tubular (CFST) columns have been used in moment frame structures because of their good seismic performance. The concrete core and the steel tube act as a composite member to create higher strength and ductility. The concrete core could delay local buckling of the steel tube while the tube may prevent splitting of the concrete core. During construction stages, the steel tubes can also be used as formworks for the wet concrete, so the needs for temporary formworks can be minimized. The shapes of CFST column sections are commonly circular or square, which is beneficial for two-way frame structures because the columns can be constructed with moment connections in both directions. In particular, the square CFST sections are more desirable for making connections due to their flat surfaces.

Various methods of connecting beams to CFST columns have been proposed and tested. These include the diaphragm-type connections as evaluated by Nishiyama, et al. (2004) and Park, et al. (2011). Li, et al. (2009) and Sheet, et al. (2013) studied the behaviour of CFST column structures with beam-end plate connections combined with through-bolts. Alternatively, blind bolts were used in beam to CFST column connections with flush endplates and with T-stubs as proposed by Wang, et al. (2009) and Yao, et al. (2008), respectively. The advantages and disadvantages of each connection type have been summarized by Chunhaviriyakul, et al. (2015).

Among the developed connection types, the direct-welded type is one of the simplest connections. In direct-welded connections the beams are welded directly to the CFST column tube walls or plates as illustrated in Fig. 1. Since there is no conflicting element inside the CFST joints, this method is suitable for two-way frame connections. However, the joints have low strength and stiffness, because each side of the tube is not interconnected and the plates can deform separately while out-of-plane forces apply. For that reason, Schneider and Alostaz (1998) emphasized that the direct-welded connections are not normally recommended for use in seismic areas, unless the tube plates are stiffened. Improvement can be made to the direct-welded connections, such as utilizing T-stiffeners as proposed by Kang, et al. (2001). Another method to improve the strength and the stiffness of CFST column connections has been proposed by Hoang, et al. (2015) and Xu, et al. (2018) with the recommendation that long bolts should be installed through the CFST sections and fastened at both ends.

Besides the CFST joint strength and stiffness, there are also issues with direct-welded connections that should be considered. Fracture on the CFST walls near the weld was observed in the tests conducted by $\mathrm{Li}$, et al. (2017). In two-way frames, early failures may occur caused by bidirectional loading interactions. The beams in perpendicular directions may reach their ultimate capacity at the same time. This negative impact of bidirectional loading may cause column yielding as found by MacRae and Tagawa (2001) and Dutta and
Kunnath (2013). Different results were obtained by Tjahjanto, et al. (2019), which found that the effects of perpendicular lateral loading on two-way beamto-CFST-column connections with external diaphragms are not significant.

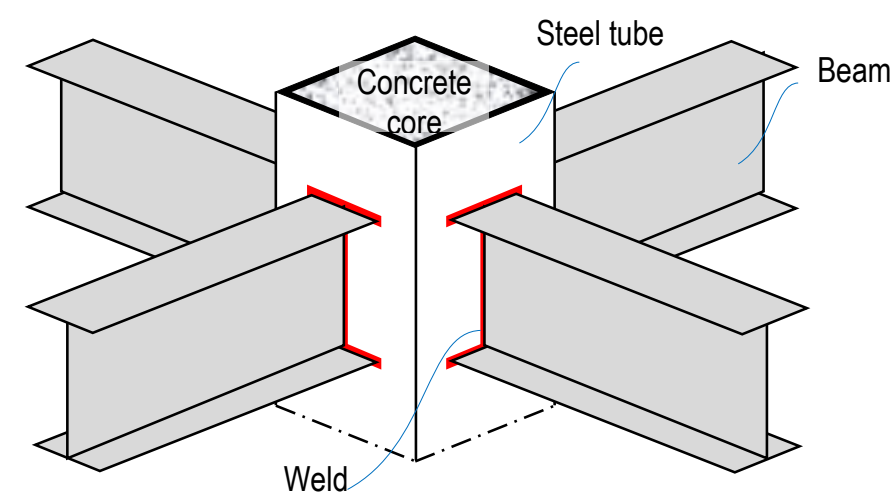

Fig. 1 Illustration of a two-way direct-welded connection in a square CFST column joint

Based on the discussion above, it is obvious that if direct welded connections are to be used, modifications are required to improve their stiffness and strength. Increasing the out-of-plane stiffness of the tube plates can improve the overall performance of the connections. From a practical point of view, it will be beneficial if the modifications do not increase the construction cost significantly. This paper describes experimental and numerical studies on improved direct-welded connections, with an emphasis on the tube-to-beam interfaces. The studies have been conducted to answer the following questions: 1) What is the likely performance of unstiffened direct-welded connections?

2) How can direct-welded connections in moment frame structures with square CFST columns be improved?

3) How does an improved direct-welded connection perform under bidirectional loading?

4) What mechanisms should be considered in design?

\section{Conceptual development}

A CFST column joint with an unstiffened direct-welded connection on one of its sides is considered. When a beam end moment occurs, a tension force from the connected beam flange is transferred to the joint through the tube plate. The tension force results in out-of-plane deformation of the column tube plate 
(Fig. 2 (a)). The maximum out-of-plane displacement normally occurs along the weld line connected to the beam tension flange (Node A). The deformation causes bending of the tube plate in the horizontal and vertical sections. In the horizontal section, the deformation at the corner of the tubes (Node B) is restricted by the side plate or web plate of the tube. While Node C and Node D are considerably far from the beam tension flange, the plate at those nodes is quite undeformed. In most cases, the plate curvature in the horizontal section (AB) is much larger compared to the curvature in the vertical section, $\mathrm{AC}$ and $\mathrm{AD}$. This makes the $\mathrm{AB}$ line become critical to the beam flange tension.

In Fig 2. (b), two pairs of through-rods are installed above and below the beam tension flange to provide additional out-of-plane restraints for the tube plate. As the curved lines in the vertical section (AC' and AD') become shorter, the plate out-of-plane stiffness increases and the curved line in the horizontal section, $\mathrm{AB}$, becomes less critical. In such a configuration, the effectiveness of the restraining to the tube plate out-of-plane deformation depends on the distance between the rods and the beam flanges. In a joint with beams welded on both directions, vertical offsets between perpendicular through-rods must be provided. Consequently, some rods are placed further from the beam flanges. By way of solution, the flexural stiffness of the tube plate can be increased by inserting washer plates underneath the nuts (Fig. 2(c)). As the nuts are fastened, the washer plates clamp the tube plate and increase its out-of-plane stiffness.

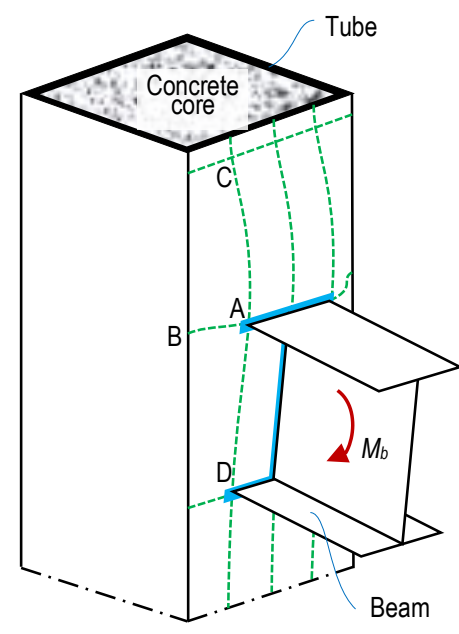

(a) Unstiffened

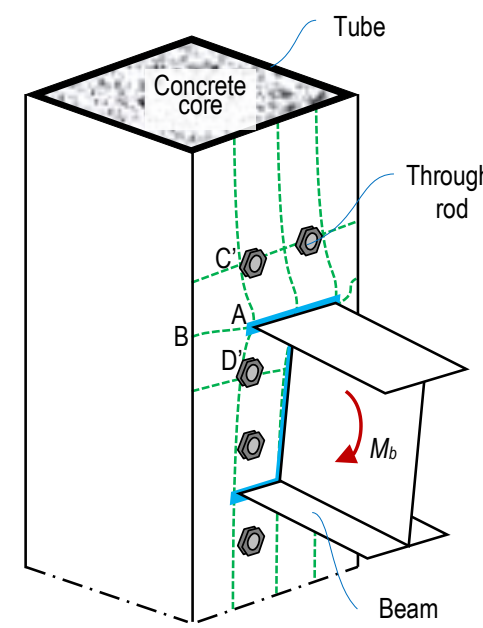

(b) With through-rods

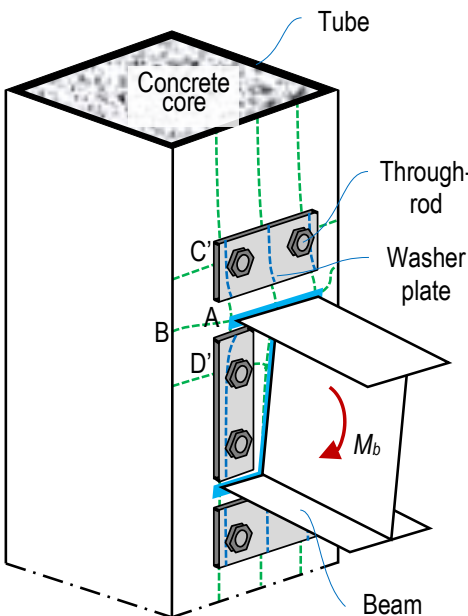

(c) With through-rods and washer plates

Fig. 2 Out-of-plane deformation of tube plates due to beam end moments

\section{Experimental program}

A moment frame subassembly with square CFST column representing an interior joint in a two-way moment frame structure under lateral loading has been tested. The subassembly consists of one CFST column and four beams which are directly welded to the column tube (Fig. 3). A universal (bidirectional) hinge was placed under the column base to allow rotations in both perpendicular horizontal axes. Lateral loadings were applied on top of the column in both directions. No axial load was applied to the column. The subassembly was designed to satisfy the strong-column-weak-beam design criteria. The CFST column was SHS $250 \times 250 \times 9\left(f_{\text {y-tube }}=311 \mathrm{MPa}\right)$ tube filled with unreinforced concrete core $\left(f_{c}{ }^{\prime}=43.8 \mathrm{MPa}\right)$. The beams were 200UB29.8 sections $f_{\text {y-beam }}=$ $354 \mathrm{MPa})$. The beams were welded to the column tube $(10 \mathrm{~mm}$ fillet weld, E48xx). Threaded M16 rods (Grade 8.8) were used as through-rods for stiffening the tube plates against out-of-plane deformations. Sliding hinge joints (SHJ) with symmetric friction connections in the bottom flange and web of the beams were used as the beam splice connections.

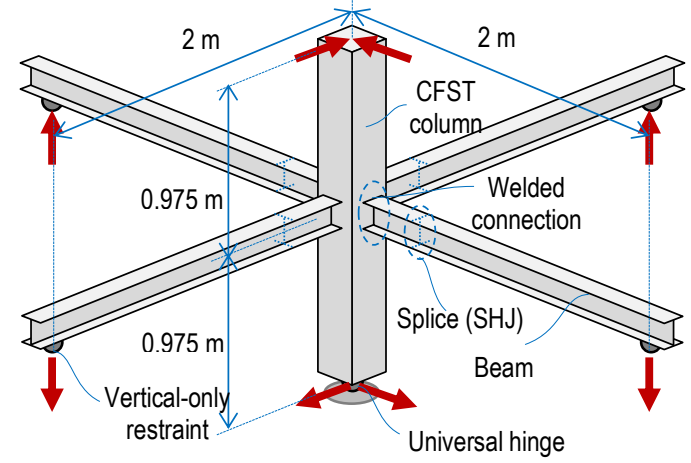

Fig. 3 Structural system and loading application of the tested subassembly

The test setup and instrumentation arrangement are shown Fig. 4 and Fig. 5. Hydraulic actuators were used to generate lateral displacements. In the W-E direction, one hydraulic actuator was attached to the top of the column. In the $\mathrm{N}-\mathrm{S}$ direction, a pair of hydraulic actuators was used to avoid the possibility of column twisting. Those actuators were parallel and programmed to result in equal displacements. Lateral-torsional buckling failure of the beams was avoided by connecting diagonal braces between adjacent beams. Global rotation of the structure at beam level was controlled by two actuators connected to the end of W-E beams. The displacement of the beam-level-actuators was programmed to be proportional to the displacement of the column-top actuators based on the elevation ratio between the corresponding points to the column base.

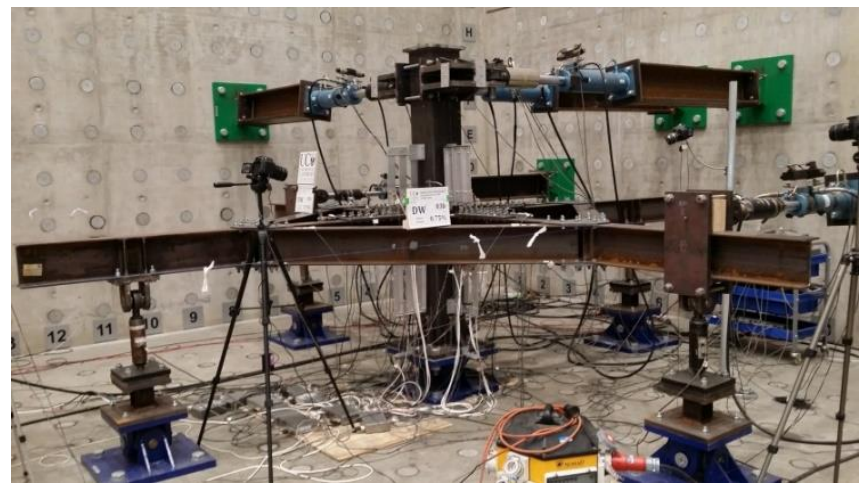

Fig. 4 The specimen and instrumentation during testing

The specimen was tested in three main stages:

1) DW-01: Unstiffened direct-welded connection (Fig. 6(a)). The throughrods had been installed through the column without nuts (unfastened).

2) DW-02: Improved direct-welded connection with through-rods (Fig. 6(b)). The rods were fastened and pretensioned.

3) DW-03: Improved direct-welded connection with through-rods and washer plates (Fig. 6(c)). Washer plates (12-mm-thick plate, Grade 300) were inserted between the tube and the nuts at both sides of the column before 
the rods were pretensioned. The connection details are shown in Fig. 7. The vertical distance between the through-rods and the beam flanges, $s_{r}$, amounted to $70 \mathrm{~mm}$ for the connection in W-E direction and $40 \mathrm{~mm}$ for the connection in $\mathrm{N}-\mathrm{S}$ direction.
The through-rods were pretensioned using the calibrated torque wrench method. The pretension force was estimated at $60 \%$ of the nominal proof load as specified in AS/NZS 1252:1996 (1996).

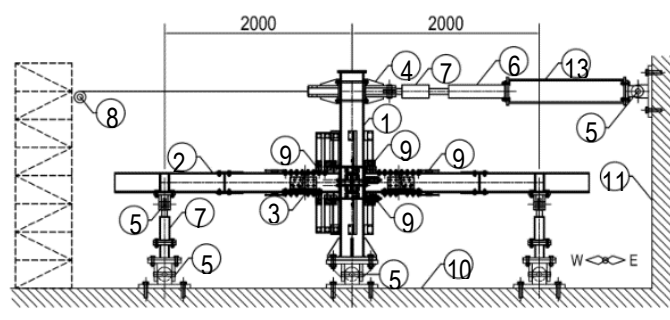

(a) W-E elevation view

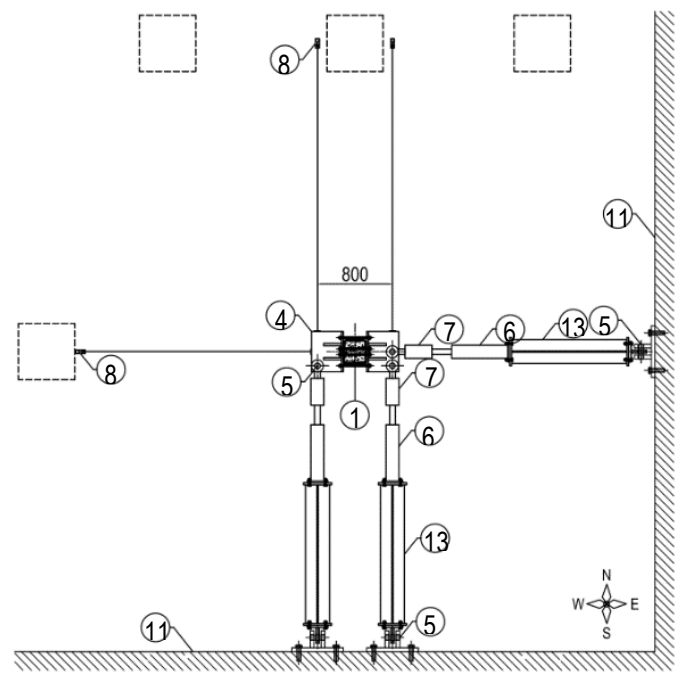

(c) Plan view at column top level

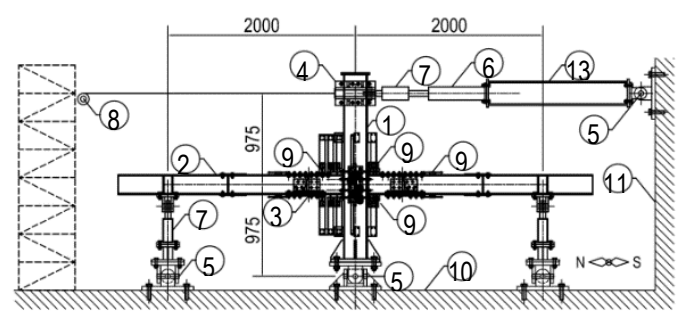

(b) N-S elevation view

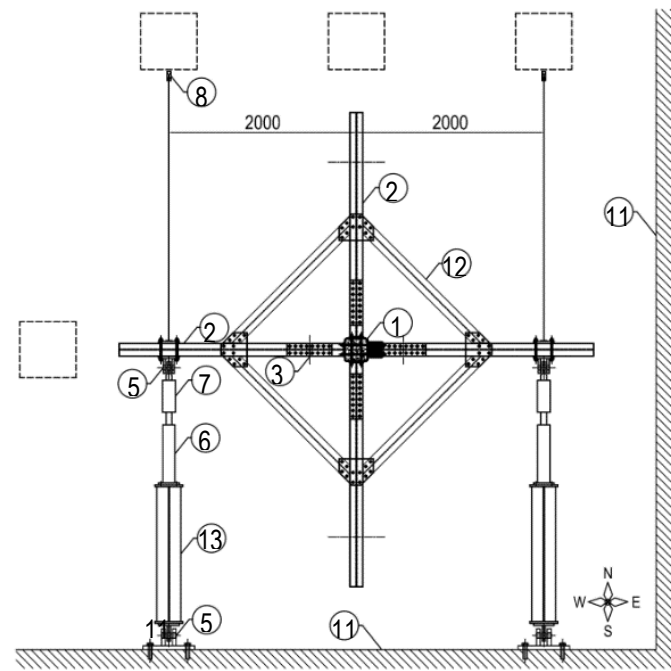

(d) Plan view at beam level

Legend: 1 - CFST column; 2 - beam; 3 -SHJ; 4 - loading bracket; 5 - universal pin; 6 - actuator; 7 - load cell; 8 string/rotary potentiometer; 9-displacement potentiometer/transducer; 10 - strong floor; 11 - strong wall; 12 - bracing beam; 13 - extension beam

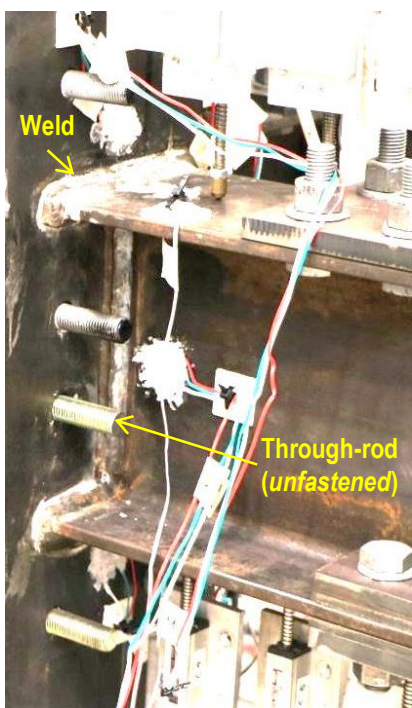

(a) DW-01 (unstiffened)

Fig. 5 Test setup

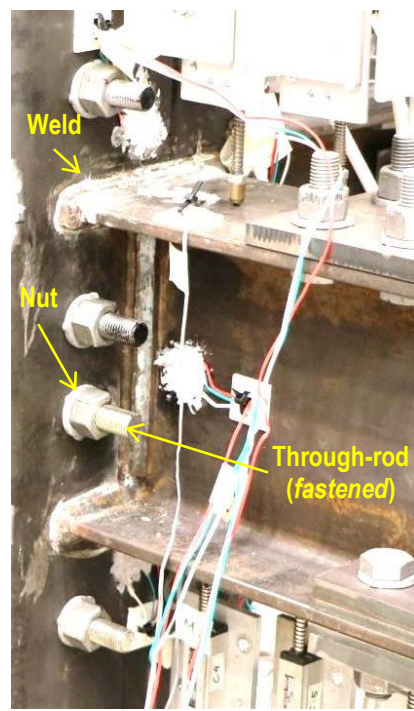

(b) DW-02 (with nuts)

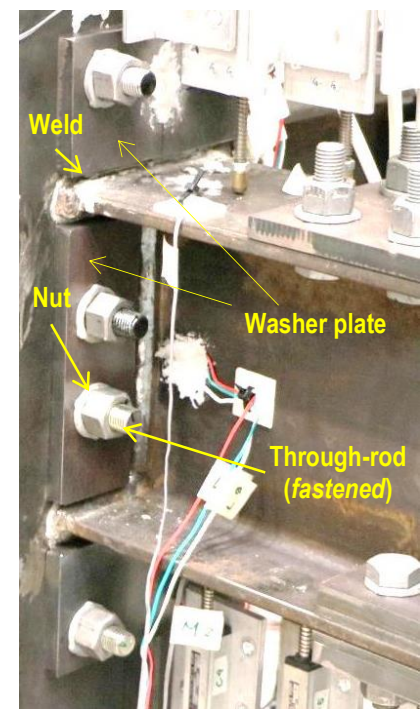

(c) DW-03 (with nuts and washer plates)

Fig. 6 Variation of the test specimen 


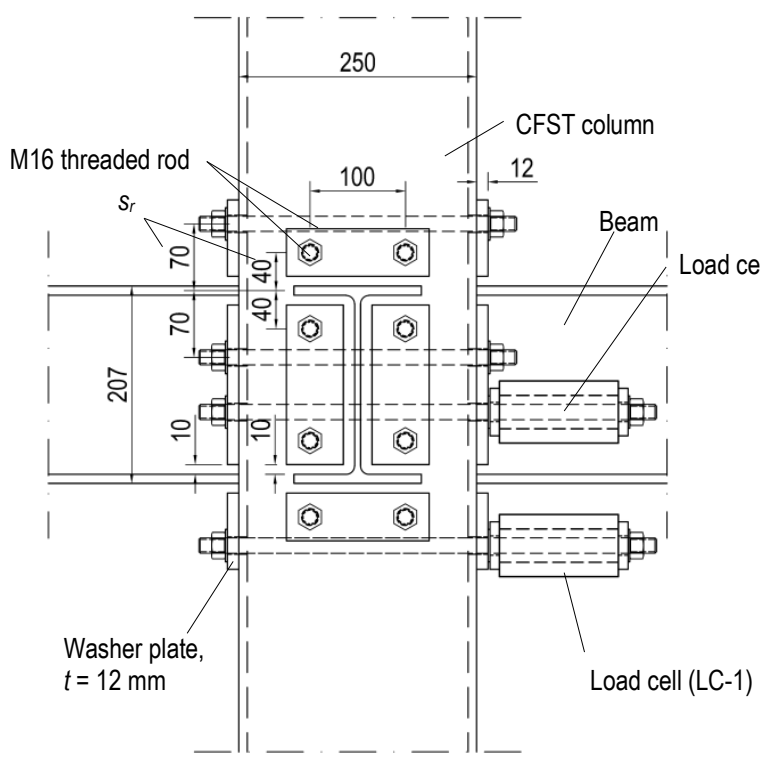

(a) Elevation view (W-E)

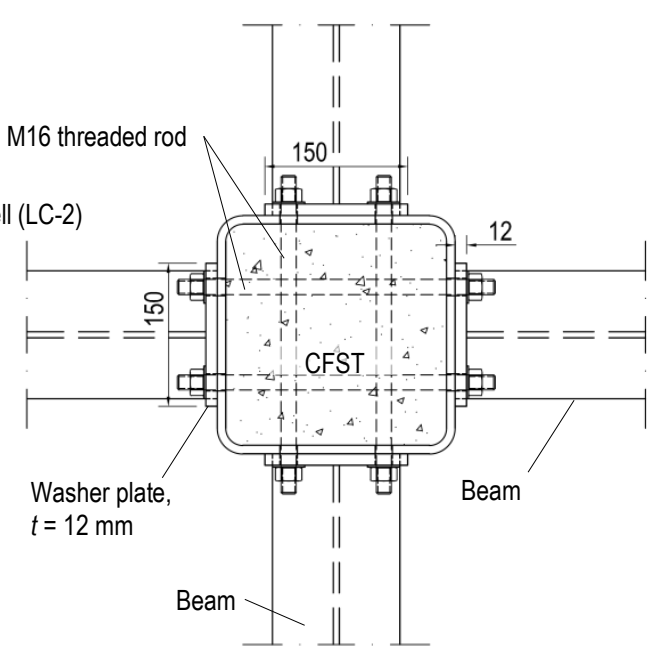

(b) Plan view

Fig. 7 Details of CFST joint with through-rods and washer plates

An integrated loading protocol was applied to control all actuators to work simultaneously. Three loading phases were conducted in each drift increment (Fig. 8): (1) three cycles in W-E direction; (2) three cycles in N-S direction; and (3) a combination of both directions to follow a cloverleaf path. The first two configurations (DW-01 and DW-02) were tested to obtain their elastic behaviour. The tests were conducted with the drift ratio limited to $0.3 \%$ to avoid any inelastic mechanisms. For the DW-03 configuration, the maximum drift ratios for each loading stage were increased gradually: $0.1 \%, 0.15 \%, 0.2 \%$,
$0.3 \%, 0.4 \%, 0.5 \%, 0.75 \%, 1 \%, 1.5 \%, 2 \%, 3 \%, 4 \%$, and $5 \%$. At these phases, inelastic mechanisms (e.g. bolt slipping in SHJ and yielding in beam or tube) were expected to occur.

An additional test (DW-04) was conducted after the test of DW-03. The beam splices were made rigid by welding the plates in the previously tested SHJ in order to generate more damage to the beam-to-column connections. The loading stages for the DW-04 test consist of one cycle in each perpendicular axis and one bidirectional cycle with a maximum drift ratio of $5 \%$.

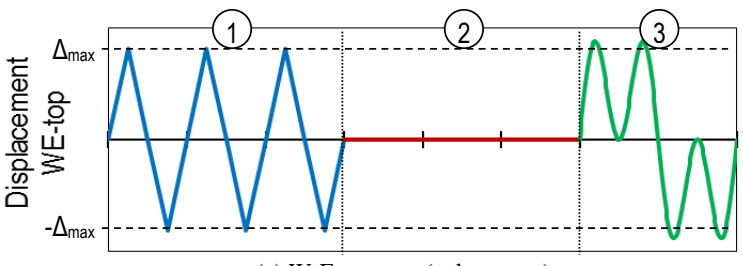

(a) W-E actuator (column top)

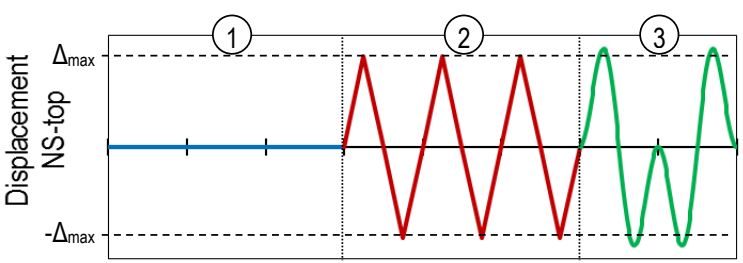

(b) N-S actuator (column top)

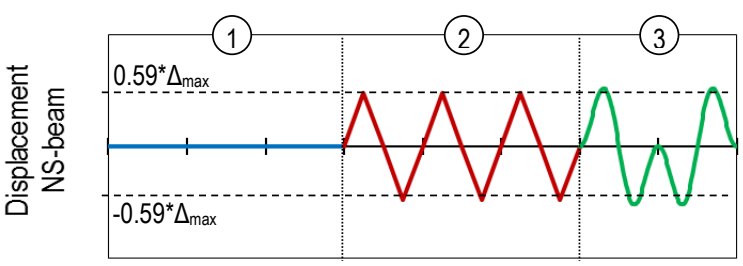

(c) N-S actuator (beam)

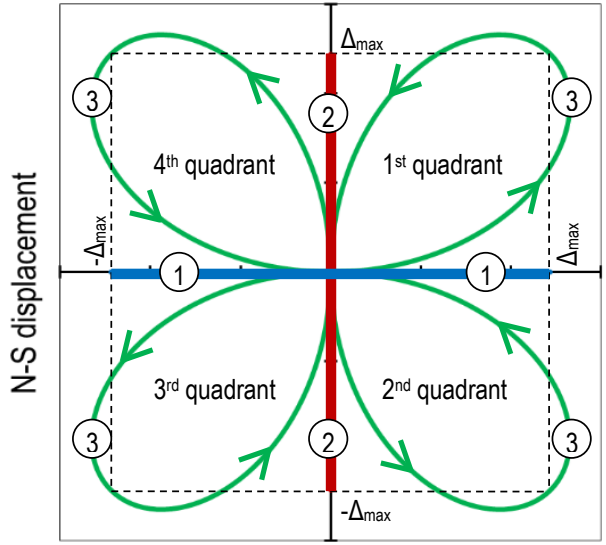

W-E displacement

Fig. 8 General loading protocols

\section{Behaviour}

\subsection{Elastic stiffness}

The connections elastic rotational stiffness is evaluated using the tests of DW-01, DW-02 and DW-03 configurations. The rotational stiffness is computed as beam end moment, $M_{b}$, divided by the relative rotation between the beams and the column at the joints as illustrated in Fig. 9. The angle of rotation, $\theta_{B}$, is calculated as the ratio of vertical displacement at point $\mathrm{B}, \delta_{B}$, to its distance to the column surface $(80 \mathrm{~mm})$. The vertical displacement was measured using a displacement transducer, which was attached to an aluminum angle bracket. The bracket was bolted to the column tube at point $\mathrm{A}$, which is assumed to be unaffected by the column tube deformation at the beam-column joint.

Beam end moment, $M_{b}$, versus angle of rotation, $\theta_{B}$, curves are shown in Fig. 10. The curves were plotted from the tests of configurations DW-01, DW 02 and DW-03 with a $0.3 \%$ drift ratio. The rotational stiffness of DW-01 is approximately $3500 \mathrm{kNm} / \mathrm{rad}$, or equal to $2.4 * E_{s} I_{b} / L_{b}$, in W-E and N-S directions. The beams flexural stiffness parameter, $E_{s} I_{b} / L_{b}$, is used for 
comparison, where $E_{s}$ is the modulus of elasticity of steel (= $\left.200 \mathrm{GPa}\right), I_{b}$ is the second moment of area of the beam section $\left(=2.91 * 107 \mathrm{~mm}^{4}\right)$, and $L_{b}$ is the span of the beam $(=2000 \mathrm{~mm})$. It is shown that the rotational stiffness is increased after the through-rods were fastened and pretensioned (DW-02) and after the washer plates were inserted (DW-03). In W-E direction, where the rodto-beam distance is longer $\left(s_{r}=70 \mathrm{~mm}\right)$, the rotational stiffness in DW-02 and DW-03 amounts to approximately $7000 \mathrm{kNm} / \mathrm{rad}$ (or equal to $4.8^{*} E_{s} I_{b} / L_{b}$ ) and $8500 \mathrm{kNm} / \mathrm{rad}$ (or equal to $5.8^{*} E_{s} I_{b} / L_{b}$ ) respectively (Fig. 10 (a)). In N-S direction, where the rod-to-beam distance is shorter $\left(s_{r}=40 \mathrm{~mm}\right)$, the rotational stiffness increases in DW-02 and DW-03 to be approximately $10500 \mathrm{kNm} / \mathrm{rad}$ (or equal to $7.2^{*} E_{s} I_{b} / L_{b}$ ) and $13000 \mathrm{kNm} / \mathrm{rad}$ (or equal to $8.9^{*} E_{s} I_{b} / L_{b}$ ) respectively (Fig. 10 (b)).

For joint rigidity classification purposes, the rotational stiffness of each configuration is compared to the ranges specified in Eurocode EN 1993-1-8 (2005). The dashed lines represent the boundaries of connection rigidity classification. All the curves lie within Zone 2 (between $0.5 E_{s} I_{b} / L_{b}$ and 25 $\left.E_{s} I_{b} / L_{b}\right)$ and can thus be classified as 'semi-rigid'.

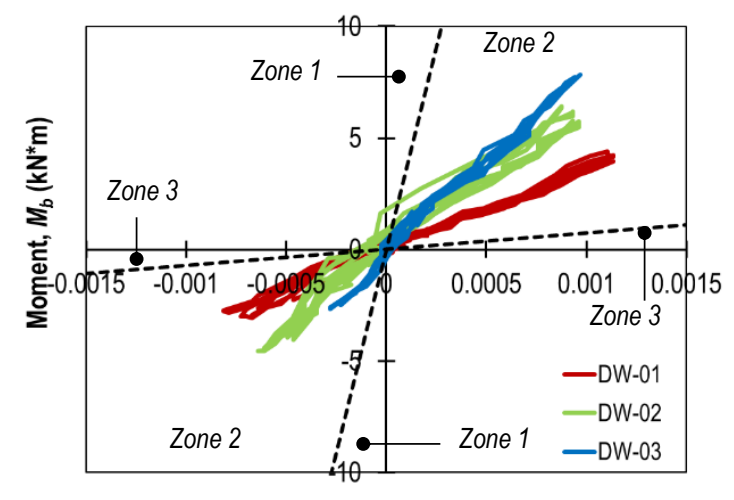

Rotation, $\theta_{b}(\mathrm{rad})$

(a) W-E direction

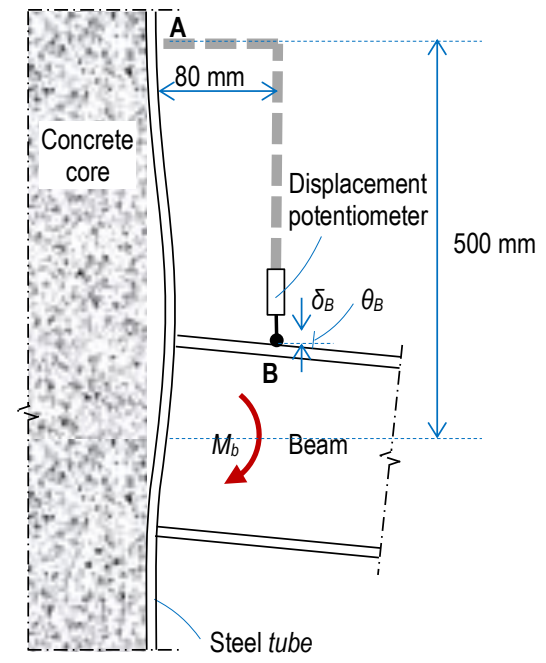

Fig. 9 Illustration of beam-column relative rotation measurement

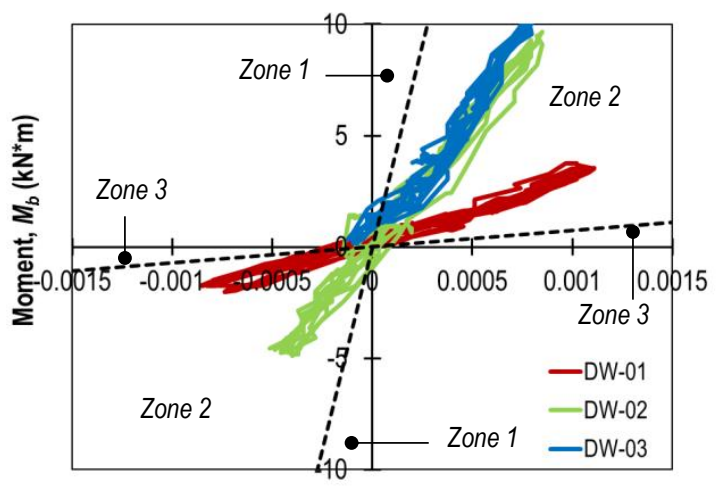

Rotation, $\theta_{b}(\mathrm{rad})$

(b) N-S direction

Fig. 10 Beam end moment versus beam-column relative rotation at $0.3 \%$ drift ratio

\subsection{Stress increment in the tube}

The stress increment in the tube is evaluated. The stress is presented in terms of von Mises stress, which is calculated from the measured strain and plotted versus the beam moment up to the $0.3 \%$ drift ratio, when the steel remained in the elastic region (Fig. 11). The strain values are obtained using rectangular strain gauge rosettes attached at the corner of the steel tube at the beam flange level. In W-E and N-S directions, with the bolt centres at $70 \mathrm{~mm}$ and $40 \mathrm{~mm}$ from the beam flange centres respectively, the stress increment in the unstiffened DW connection (DW-01) is estimated at approximately 13 $\mathrm{MPa} / \mathrm{kNm}$. The predicted corresponding yielding moment is $24 \mathrm{kNm}$ to reach the yield strength of the tube $\left(F_{y}=311 \mathrm{MPa}\right)$. In W-E direction (Fig. 11(a)), the stress increment of DW-02 and DW-03 is estimated at approximately 7
$\mathrm{MPa} / \mathrm{kNm}(54 \%$ of the rate of DW-01) and $6 \mathrm{MPa} / \mathrm{kNm}(46 \%$ of the rate of DW-01), respectively. This implies that stiffening the tube with through-rods and washer plates can delay yielding at the column corner to twice the yielding moment of the unstiffened connection.

More significant improvement is obtained in N-S direction because the rods are closer to the beam flanges and make the tube more effectively restrained for out-ouf-plane deformation (Fig. 11(b)). The von Mises stress rates of DW-02 and DW-03 are $3.5 \mathrm{MPa} / \mathrm{kNm}(27 \%$ of the rate of DW-01) and $2.5 \mathrm{MPa} / \mathrm{kNm}$ (19\% of the rate of DW-01), respectively. From the results, it can be concluded that reducing the distance between the rods and the beam flange can significantly delay yielding at the column corner.

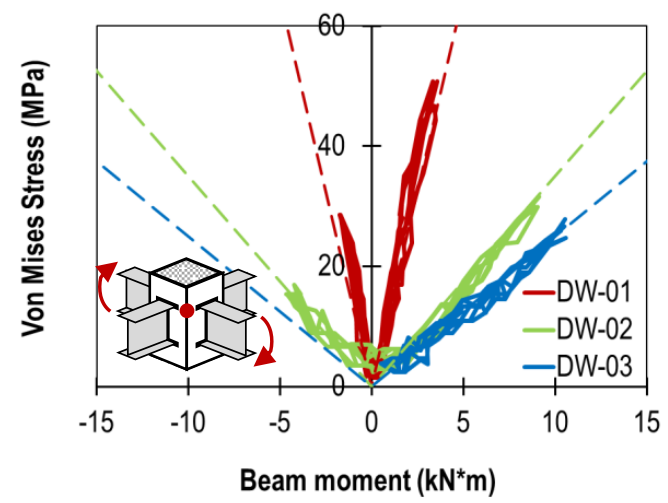

(b) N-S direction

(a) W-E direction

Fig. 11 Von Mises stress (at tube corner) versus beam end moment at $0.3 \%$ drift ratio 


\subsection{Hysteretic behaviour}

The hysteretic behaviour of DW-03 (continuous lines) and DW-04 (dashed lines) under one-way and two-way loadings is shown in Fig. 12. The loading stages for DW-03 range from a $0.1 \%$ to a $5 \%$ drift ratio. The DW-04 configuration, where the beam splices are made rigid after the final loading series of DW-03, has been tested for the 5\% drift ratio. The subassembly hysteretic behaviour in W-E direction and the one in N-S direction are plotted in Fig. 12(a) and (c) respectively.

The beam-to-column connection in N-S direction has better energy dissipation which is indicated by the less-pinched shape in hysteretic curves. The lateral force capacities of the subassembly in both directions are less than the predicted corresponding lateral force at the beam yield moment, $M_{y b}$. Declining of the structure lateral capacity was caused by two factors: (1) different beam flange behaviour under tension and compression forces which causes unsymmetrical stress distribution along the beam depth; and (2) sliding of the friction connections in the SHJs. The first causes early yielding $(\varepsilon \geq$ 0.0015 ) which occurs in the compression flanges, especially if the rods are far from the flanges, as shown in Fig. 13(a). The effect of unsymmetrical stresses in beams is less significant if the rods are close to the beam flanges (Fig. 13(b). Yielding in the middle of the beam compression flange occurs when the strain exceeds the yield strain $\left(\varepsilon \geq \varepsilon_{y}=0.0015\right)$.

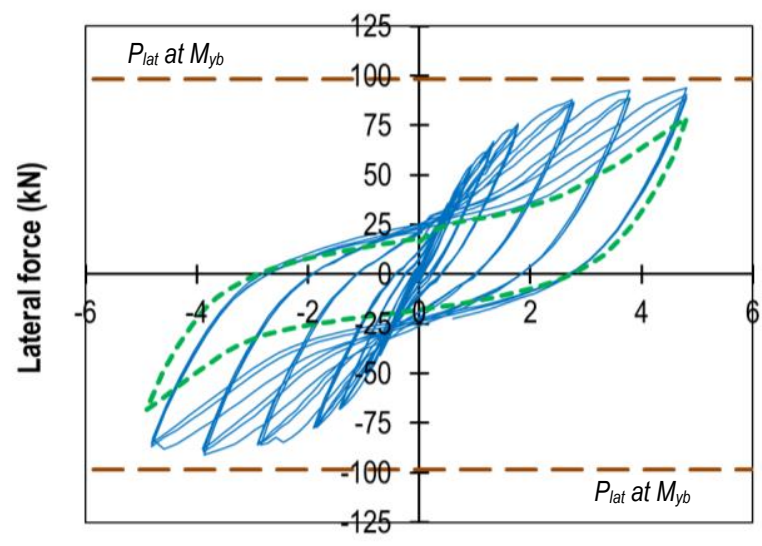

Drift ratio (\%)

(a) W-E direction $\left(s_{r}=70 \mathrm{~mm}\right)$, one-way

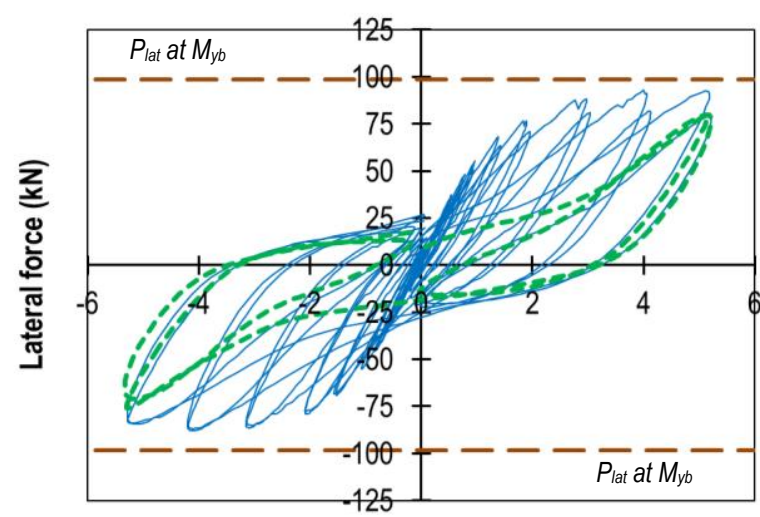

Drift ratio $(\%)$

(c) W-E direction $\left(s_{r}=70 \mathrm{~mm}\right)$, two-way

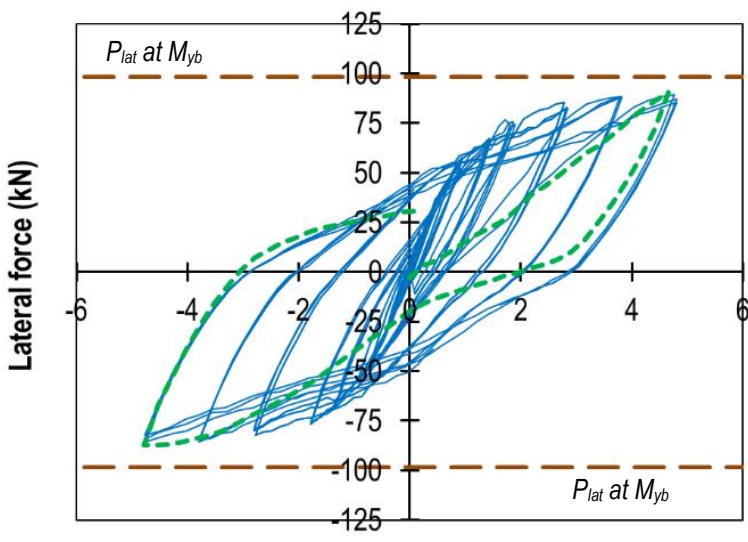

Drift ratio (\%)

(b) N-S direction $\left(s_{r}=40 \mathrm{~mm}\right)$, one-way

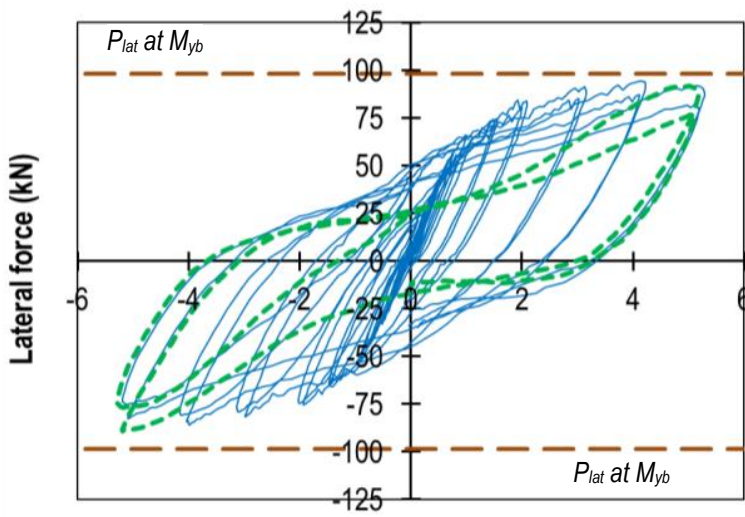

Drift ratio (\%)

(d) N-S direction $\left(s_{r}=40 \mathrm{~mm}\right)$, two-way

Fig. 12 Hysteresis curves of lateral force versus displacement of ED-03

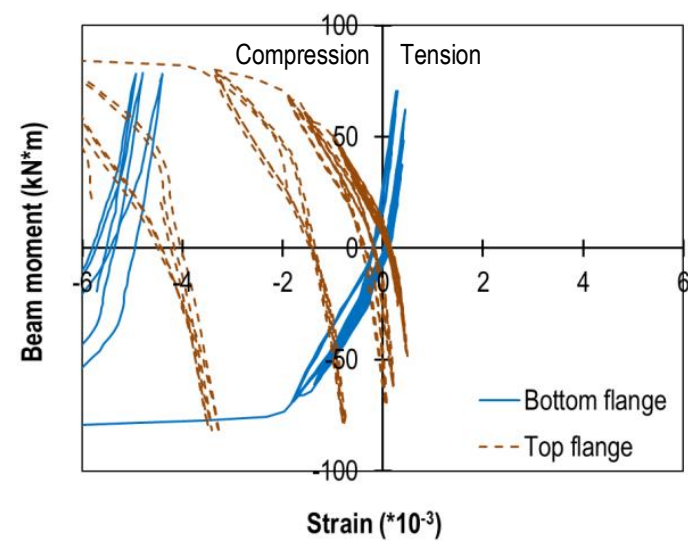

(a) W-E direction

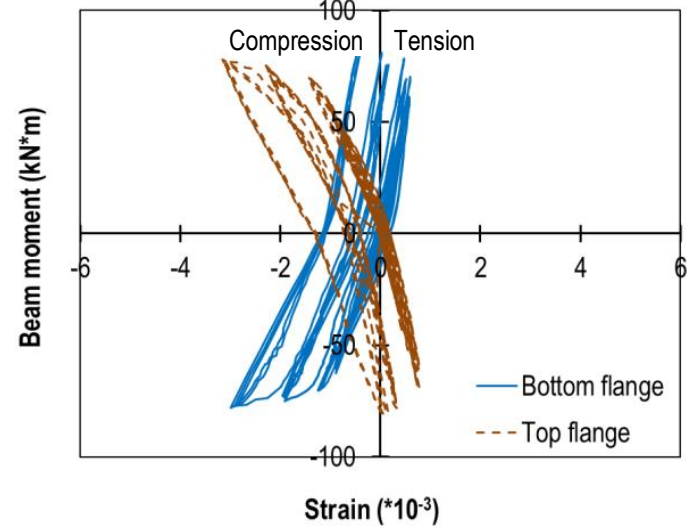

(b) N-S direction 


\subsection{Component deformations}

The relative rotation between the beam and the column is computed at the tube and at the beam, as illustrated in Fig. 14. The contribution of the tube, $\theta_{t}$, is calculated from the out-of-plane displacement of the tube plate (Node C), $\delta_{t}$, divided by the distance between Node $\mathrm{C}$ to the beam compression flange (Fig. 14(a)). The total joint rotation, which is computed at the beam, $\theta_{b}$, is the relative vertical displacement of the beam near the joint (Node B), $\delta_{b}$, divided by the distance between Node B to the connection (Fig. 14(b)). The hysteretic curves of the beam end moment versus rotations, $\theta_{b}$ and $\theta_{t}$, for both W-E and N-S directions are plotted in Fig. 15. There are significant differences between the tube contribution, $\theta_{t}$, and the total rotation, $\theta_{b}$, which indicate that large inelastic deformation occurred at the beam-to-tube welded connection.

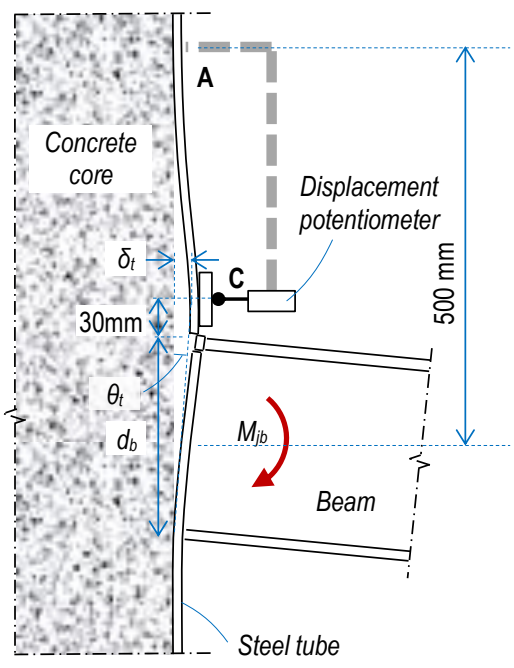

(a) At steel tube
The effect of the distance of the rods to the beam flanges, $s_{r}$, can be found by comparing the curves of W-E and N-S directions. In W-E direction, where $s_{r}$ is longer $(70 \mathrm{~mm})$, the maximum rotation of the tube is $0.009 \mathrm{rad}$ and the beam rotation is $0.036 \mathrm{rad}$. In N-S direction, the maximum rotation of the tube is 0.004 rad and the beam rotation amounts to $0.029 \mathrm{rad}$.

The beam end moments, $M_{b}$, versus relative rotation at beam splices are plotted in Fig. 16. The W-E direction is depicted in Fig. 16(a) and the N-S direction in Fig. 16(b). The rotations are mostly caused by sliding in the friction connections on bottom flanges. Sliding of the friction connections occurred at approximately $M_{b}=60 \mathrm{kNm}$, or equal to an effective friction coefficient, $\mu_{i}=$ 0.34 . The sliding resistance increases gradually until the beam end moments reach $80 \mathrm{kNm}$ with the corresponding friction coefficient, $\mu=0.45$.

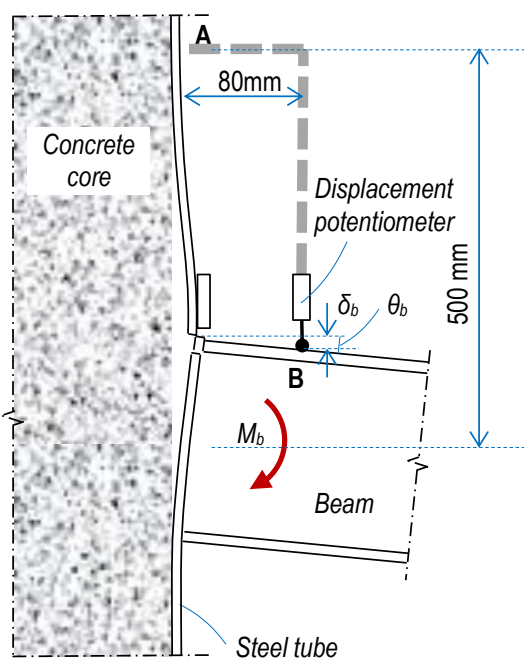

(b) At beam

Fig. 14 Illustration of beam-tube deformation discontinuity measurement

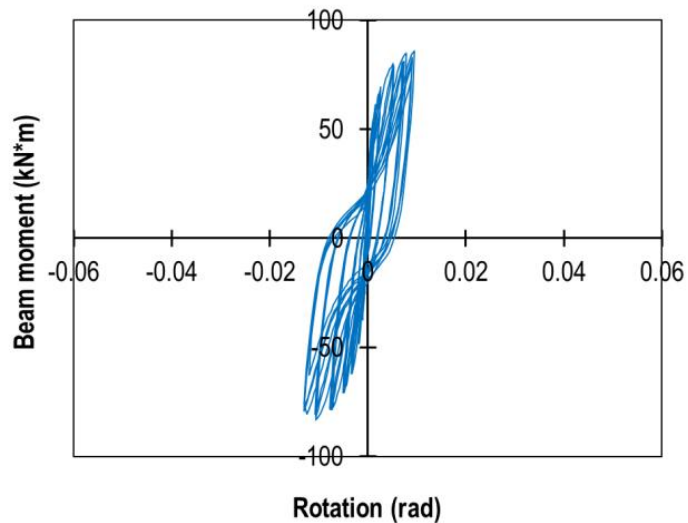

(a) At tube, $\theta_{t}$ (W-E direction)

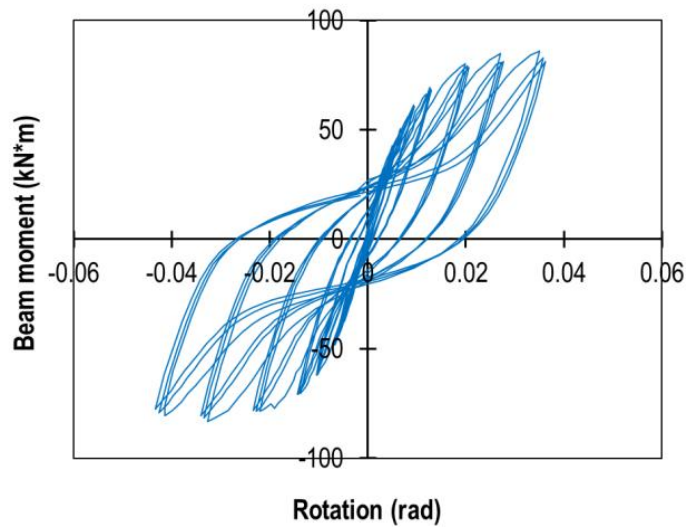

(c) At beam, $\theta_{b}$ (W-E direction)

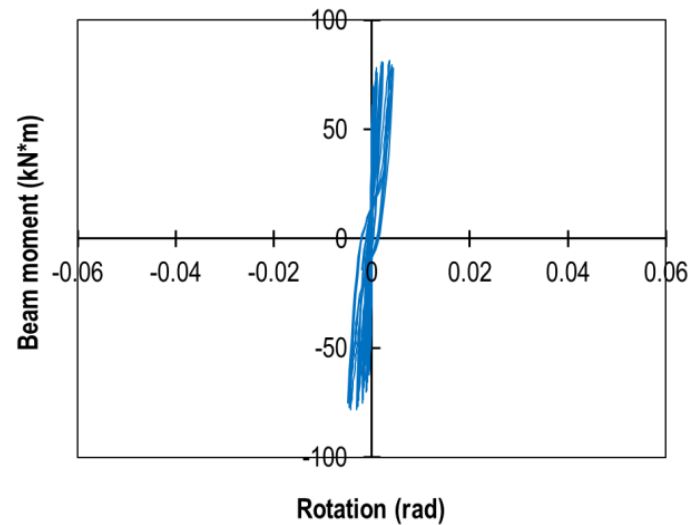

(b) At tube, $\theta_{t}$ (N-S direction)

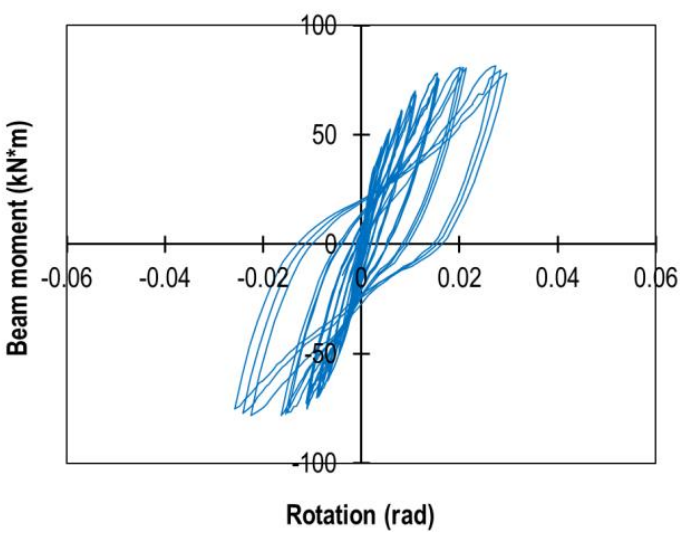

(d) At beam, $\theta_{b}$ (N-S direction) 


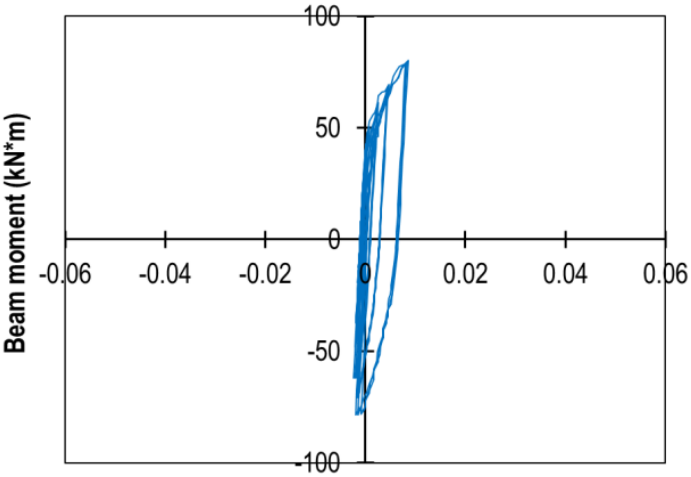

Rotation (rad)

(a) W-E direction

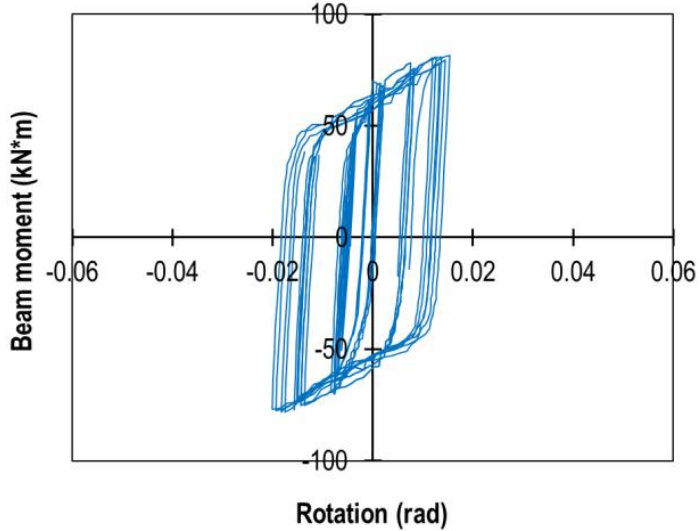

(b) N-S direction

Fig. 16 Beam end moment versus rotation at splices (DW-03)

The relative rotation contribution of each component in the subassembly is presented in Fig. 17. For the W-E direction (Fig. 17(a)) and N-S direction (Fig. 17(b)), the inelastic deformations (joint + splice) are the major contributor to

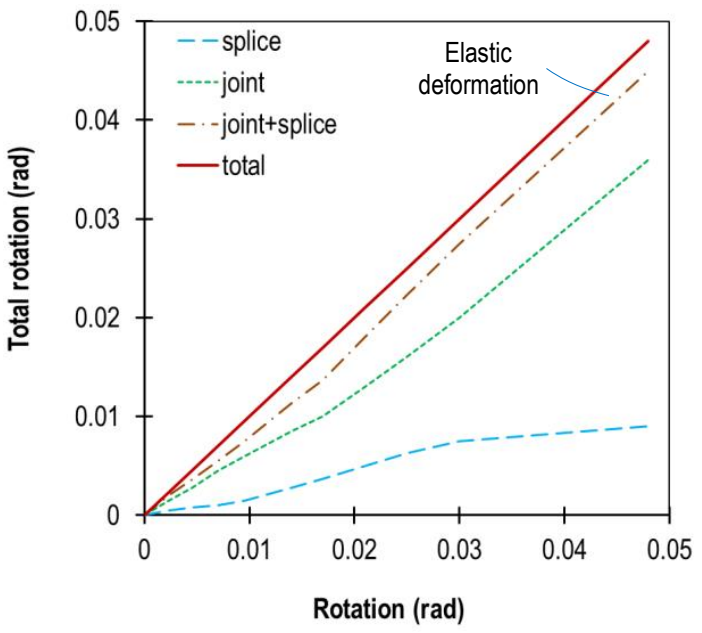

(a) W-E direction the total rotations, especially when the total rotation is larger than $0.015 \mathrm{rad}(1.5 \%$ drift ratio). In both directions, the contributions of inelastic deformations (joint + splice) are about $94 \%$ of the total rotations at the $5 \%$ drift ratio.

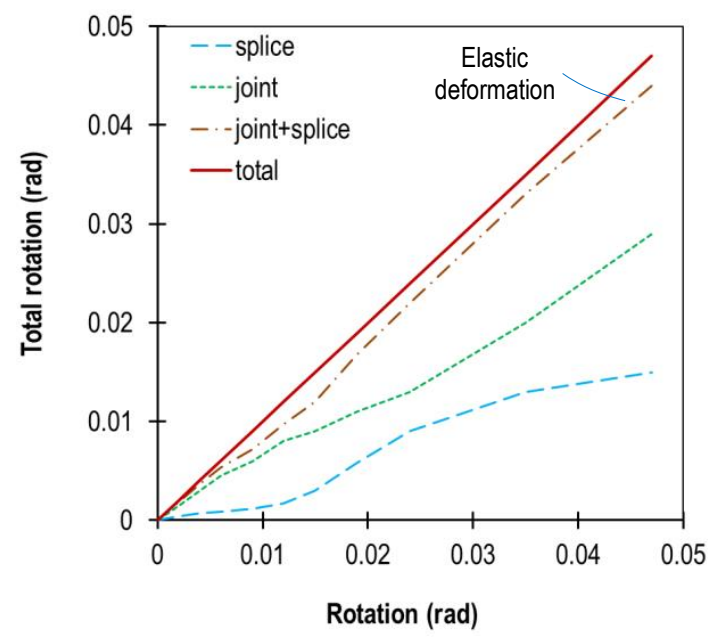

(b) N-S direction

Fig. 17 Component rotations of DW-03

\subsection{Failure modes}

Large inelastic deformations at the joints are indicated in the discontinuity between the deformations measured at the tube and the beams. Observation shows that local deformations at the welded connections are mainly caused by fractures in the tube due to tension forces from the beam flanges. Fracture of the tube plates was initiated from the tip of the beam flanges and propagated to the

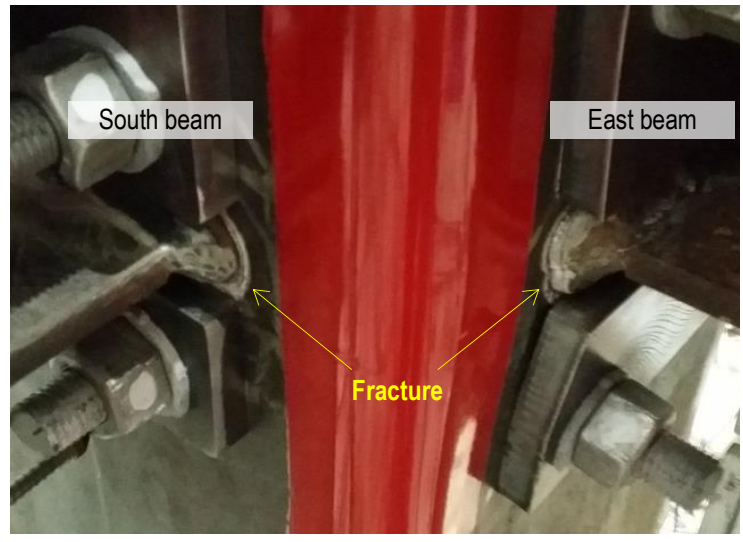

(a) Bottom flanges middle of the tube as the loading increased. The visible cracks in the tube were first observed at the $2 \%$ drift ratio loading stage in W-E direction and at the $4 \%$ drift ratio loading stage in N-S direction. The fractured tube at the peak of bidirectional loading phase (5\% drift ratio) is shown in Fig. 18. By comparing the crack width of the adjacent beam flanges, it can be implied that the tube plate damage in $\mathrm{W}$-E direction is larger than the one in N-S direction.

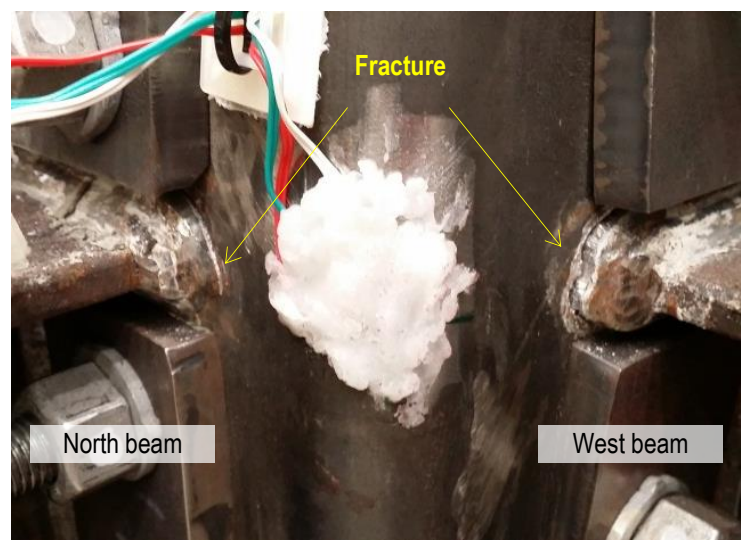

(b) Top flanges 
The through-rods tension forces were measured in the W-E direction using hollow cylindrical load cells that were inserted between the nuts and washer plates on an outer rod (LC-1) and an inner rod (LC-2), as arranged in Fig. 7. The pretension forces applied to the rods were approximately $60 \%$ of the nominal proof load, $N_{t}$, whose value is $95 \mathrm{kN}$ for M16 Grade 8.8 bolt/rod (AS 1252).
The tension forces versus beam end moment hysteretic curves are plotted in Fig. 19. It is shown that the incremental rate of tension forces in the outer rods is approximately $80 \%$ of the inner rods under positive beam end moments. The rod tension forces are relatively constant under the negative moments, indicating the rods are in the compression zones.

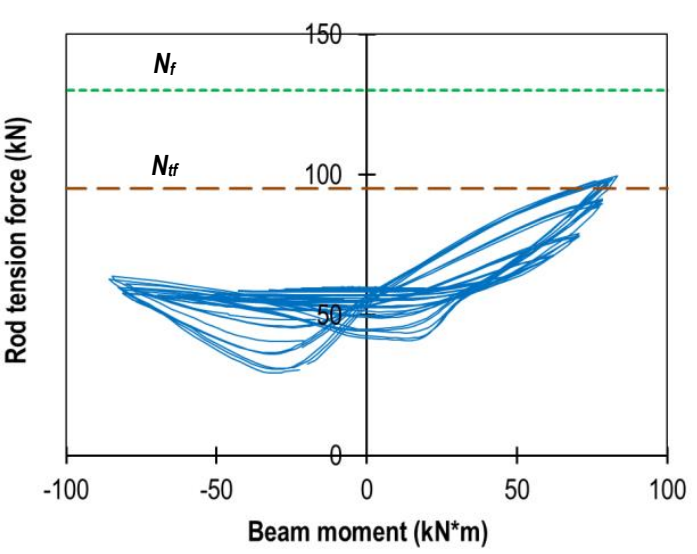

(b) Inner rod (LC-2)

Fig. 19 Rod tension forces versus beam end moment (W-E direction)

As the concrete core damage cannot be observed during the tests, some parts of the column tube plates are removed after the ultimate test of the DW04 configuration. Fig. 20 shows the indication of cone pull-out failure of the concrete around the through-rods in the $\mathrm{N}-\mathrm{S}$ direction. However, there is no visible crack or concrete failure indication in the $\mathrm{W}$-E direction.
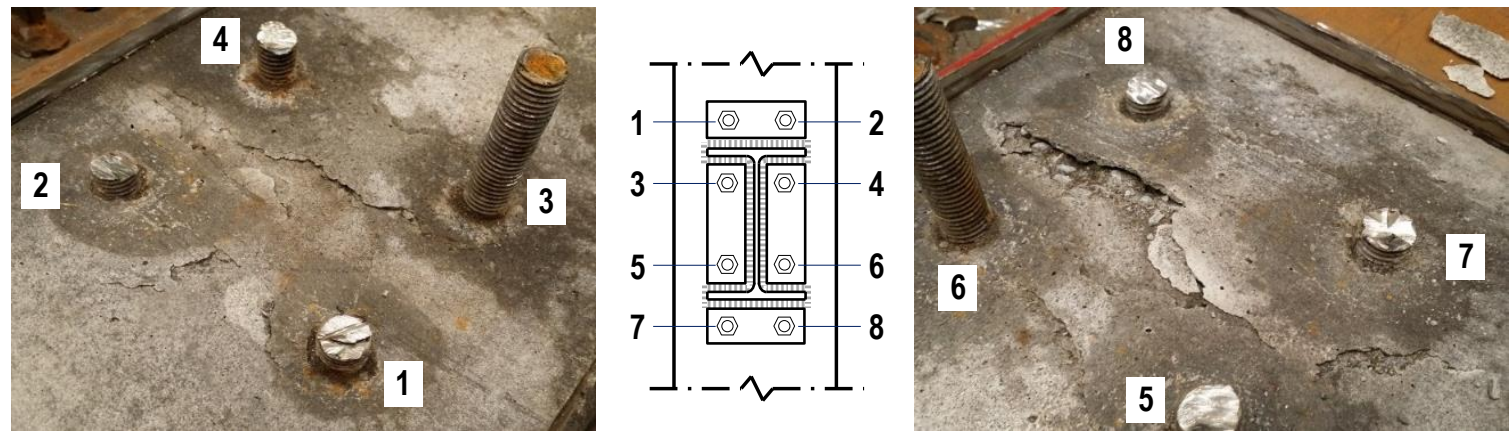

Fig. 20 Concrete cone pull-out failure in N-S direction after testing of DW-04

\section{Numerical Analysis}

\subsection{Finite element model}

Finite element analyses (FEA) have been conducted to evaluate the local behaviour of the beam-to-column interface, especially the tube fracture mechanism. The analyses were carried out using ABAQUS (SIMULIA 2012), simulating the behaviour of the connection in one considered direction, as shown in Fig. 21. The model consisted of one beam and a half-modeled CFST column. All steel plates were modeled as homogenous shell elements (S4R) with elasto-plastic materials $\left(f_{\text {y-beam }}=354 \mathrm{MPa}, f_{\text {y-tube }}=311 \mathrm{MPa}\right)$. The concrete core in the CFST column was modeled as solid or brick elements (C3D8R) with a linearly elastic material. Interactions of concrete-to-steel and steel-to-steel surfaces are defined to have normal-hard-contact behaviour. Welded connection between the beam and the tube was defined as the 'tie' constraint between the paired nodes.

Three direct-welded connection configurations were evaluated, namely: (1) unstiffened; (2) stiffened with through-rods; and (3) stiffened with through-rods and washer plates, as described in Fig. 21. In the stiffened connections, throughrods were modeled as one-dimensional beam elements. The embedded parts of the rods were constrained to the concrete core to imply fully bonded interactions. The nuts were modeled as rigid shell element, linked to the end of the rods.
Pretension forces in the rods were applied using a method similar to what had been conducted by Cipitioglu et al. (2002). The typical modelling stages are: (1) in the initial step, the length of the rod was made shorter than the total thickness of the connected parts; (2) longitudinal displacement was applied to the nut until the rod length exceeded the total thickness of the connected parts; (3) the nut displacement was deactivated and the contact interaction between the nut and the tube surfaces was activated.

Variations were made for the stiffened connections: the vertical distance between the rods and beam flanges $\left(s_{r}=40 \mathrm{~mm}\right.$ and $\left.s_{r}=70 \mathrm{~mm}\right)$; the rods pretension forces $\left(10 \% N_{t f}\right.$ and $\left.90 \% N_{t f}\right)$; and washer plates thicknesses $\left(t_{w p}=12\right.$ $\mathrm{mm}$ and $\left.t_{w p}=25 \mathrm{~mm}\right)$. The models with $10 \% N_{t f}$ were analyzed to represent a joint with snug tightened rods and the models with $90 \% N_{t f}$ were analyzed to represent a joint with proof-loaded rods considering long-term loss of the rods pretension forces. By way of comparison, derived from an indicative study which was conducted separately, the average of the pretension losses of the rods is $5 \%$, measured at 8 months after pretensioning.

The nomenclature for each configuration describes: the connection type (U for unstiffened; R for with rods; RW for with rods and washer plates) - vertical distance of the rods to beam flange (in $\mathrm{mm}$ ) - pretensioning force of the rods (in \% to nominal proof load, $N_{t f}$ ) - washer plate thickness (in $\mathrm{mm}$ ). For example: the model of RW-70-10-12 represents the configuration with rods $(70 \mathrm{~mm}$ distance to flange, $10 \% N_{t f}$ pretension) and washer plates $\left(t_{w p}=12 \mathrm{~mm}\right)$. 

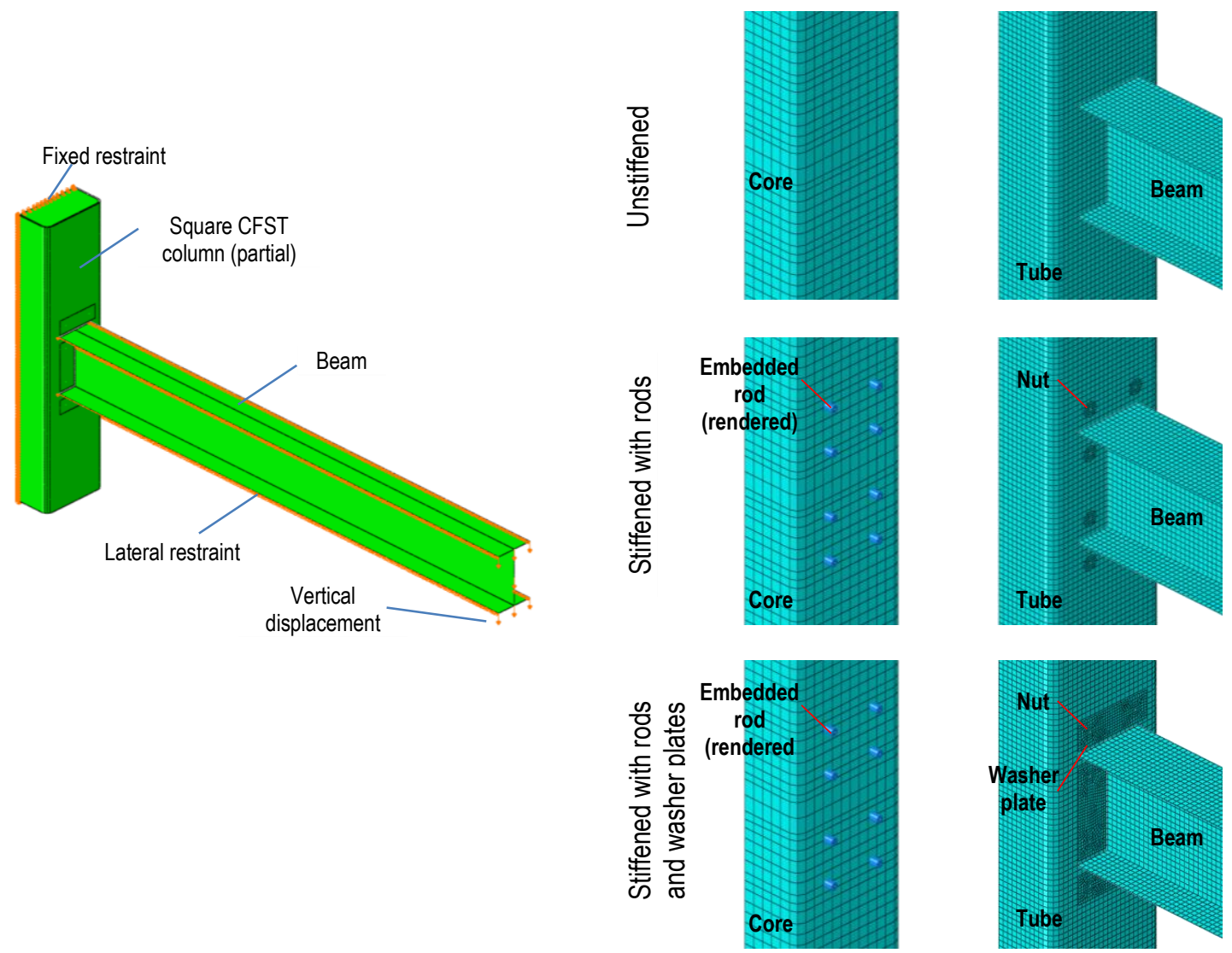

Fig. 21 Finite element modeling

\subsection{Numerical results}

The distributions of tension stress in beam flange due to beam moment are plotted in Fig. 22, in terms of ratio of nodal stress, $\sigma$, to estimated flange tension stress, $\sigma_{e s t}$, and the relative distance to the beam flange middle point (as the ratio to beam flange width, $b_{f}$ ). The estimated flange tension stresses are calculated with Eq. (1). The equation takes the assumption that the beams remain elastic as the fracture of the tube is expected to occur earlier than the beam yielding.

$\sigma_{e s t}=\frac{M_{b}}{Z_{x b}}$

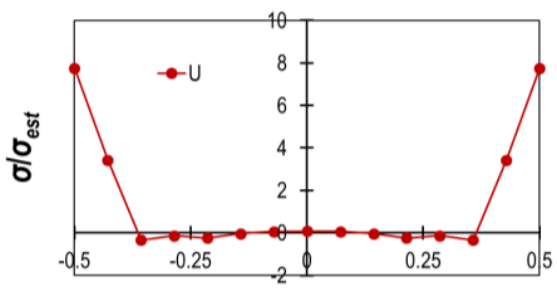

Distance to flange center $\left(\times b_{f}\right)$

(a) Unstiffened

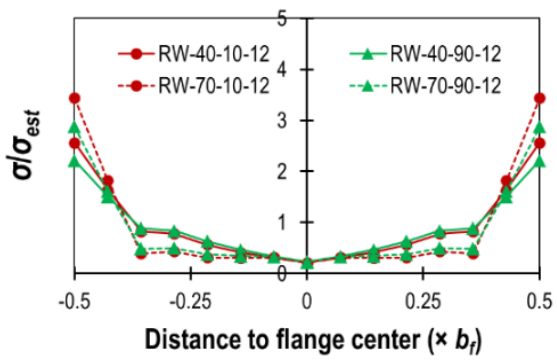

(c) With through-rods and washer plates, $t_{w p}=$ $12 \mathrm{~mm}$ where:

$M_{b}$ is the beam end moment;

$Z_{x b}$ is the beam elastic section modulus

It can be seen that in all configurations, the tension stresses in beam flanges are not uniformly distributed. The maximum stresses, $\sigma_{\max }$, are sharply located at the tip of the beam flange which can initiate out-of-plane shear failure mechanisms in the tube plates. Table 1 summarizes the stress concentration factors, $f_{\sigma}$, which are computed as $\sigma_{\max } / \sigma_{\text {est }}$ for all considered configurations. The lower stress concentration factors in configurations with through-rods and washer plates imply that stiffening the tube plates can reduce the possibility of pull-out fracture in the tube plates.

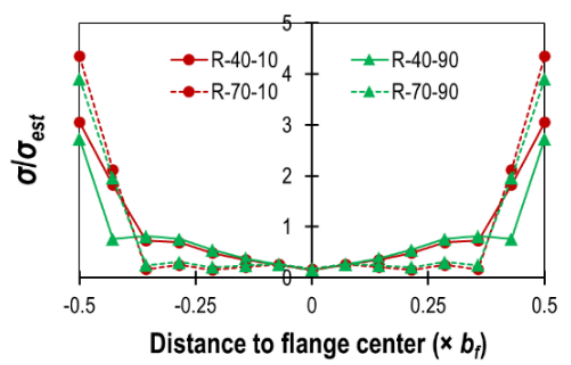

(b) With through-rods

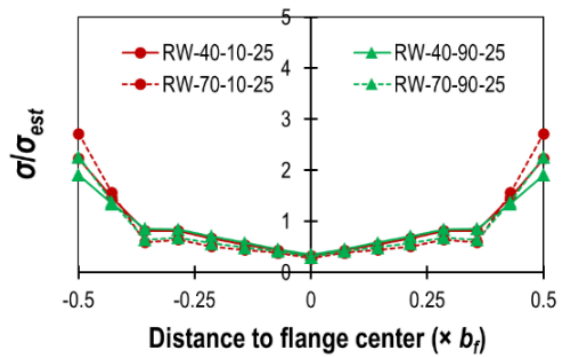

(d) With through-rods and washer plates, $t_{w p}=$ $25 \mathrm{~mm}$ 
Table 1

Tension stress concentration factor along beam flange

\begin{tabular}{|c|c|c|c|}
\hline $\begin{array}{c}\text { Rod } \\
\text { distance, } s_{\text {rod }}\end{array}$ & $\begin{array}{c}\text { Rod } \\
\text { pretension } \\
\text { force }\end{array}$ & $\begin{array}{c}\text { Washer plate } \\
\text { thickness, } t_{w}\end{array}$ & $\begin{array}{c}\text { Stress concentration } \\
\text { factor }\left(f_{\sigma}=\sigma_{\text {max }} / \sigma_{\text {est }}\right)\end{array}$ \\
\hline \multicolumn{3}{|c|}{ Unstiffened } & 7.76 \\
\hline $70 \mathrm{~mm}$ & $10 \% N_{t f}$ & No washer plate & 4.35 \\
\hline $70 \mathrm{~mm}$ & $90 \% N_{t f}$ & No washer plate & 3.90 \\
\hline $40 \mathrm{~mm}$ & $10 \% N_{t f}$ & No washer plate & 3.81 \\
\hline $40 \mathrm{~mm}$ & $90 \% N_{t f}$ & No washer plate & 2.73 \\
\hline $70 \mathrm{~mm}$ & $10 \% N_{t f}$ & $12 \mathrm{~mm}$ & 2.72 \\
\hline $70 \mathrm{~mm}$ & $90 \% N_{t f}$ & $12 \mathrm{~mm}$ & 2.56 \\
\hline $40 \mathrm{~mm}$ & $10 \% N_{t f}$ & $12 \mathrm{~mm}$ & 2.23 \\
\hline $40 \mathrm{~mm}$ & $90 \% N_{t f}$ & $12 \mathrm{~mm}$ & 2.88 \\
\hline $70 \mathrm{~mm}$ & $10 \% N_{t f}$ & $25 \mathrm{~mm}$ & 2.26 \\
\hline $70 \mathrm{~mm}$ & $90 \% N_{t f}$ & $25 \mathrm{~mm}$ & 2.22 \\
\hline $40 \mathrm{~mm}$ & $10 \% N_{t f}$ & $25 \mathrm{~mm}$ & 1.91 \\
\hline $40 \mathrm{~mm}$ & $90 \% N_{t f}$ & $25 \mathrm{~mm}$ & \\
\hline
\end{tabular}

\section{Design formulation}

\subsection{Stress concentration factor}

In order to avoid early failure, the column tubes and the welded connections along the beam flanges should have sufficient capacity to resist out-of-plane shear induced by tension forces from the beam flanges. The demand can be expressed in term of shear force per unit length, $V_{t}^{*}$, which can be calculated as the beam flange tension stress multiplied by the flange thickness, $t_{f}$. A stress concentration factor, $f_{\sigma}$, must be taken into account to compensate the sharply distributed stresses near the beam flange tips, as follows:

$$
V_{t}^{\prime}=f_{\sigma} \sigma_{e s t} t_{f}
$$

From FE results, it is found that $f_{\sigma}$ is influenced by the rod arrangement, rod pretension forces, and washer plate thickness. In Fig. 23, the relationship between $f_{\sigma}$ and a non-dimensional geometrical parameter is plotted for different rod pretension levels, $10 \% N_{t f}$ and $90 \% N_{t f}$. The stress concentration factor, $f_{\sigma}$, can be calculated with the following equations:

For snug-tightened rods $\left(10 \% N_{t f}\right)$ :

$f_{\sigma}=4.5 \times\left[\frac{L_{e}{ }^{2} b_{w p}\left(t_{w p}{ }^{3}+t_{t}{ }^{3}\right)}{L_{w p}{ }^{3} t_{t}^{3}}\right]^{-0.15}$

For proof loaded rods $\left(90 \% N_{t f}\right)$ :

$f_{\sigma}=4.9 \times\left[\frac{L_{e}{ }^{2} b_{w p}\left(t_{w p}{ }^{3}+t_{t}^{3}\right)}{L_{w p}^{3} t_{t}^{3}}\right]^{-0.13}$ where:

$L_{e}$ is the clearance between the beam flange tips to the column edges; $b_{w p}$ is the outer washer plate width $\left(\geq b_{f}\right)$;

$t_{w p}$ is the washer plate thickness;

$t_{t}$ is the tube plate thickness;

$L_{w p}$ is the washer plate outstand length which contributes to transferring the force to the rods.
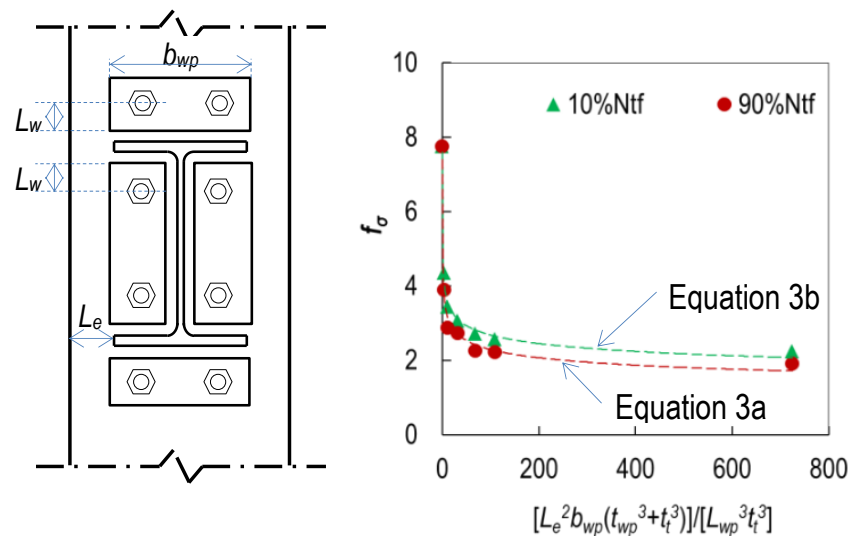

Fig. 23 Stress concentration factor, $f_{\sigma}$, formulation

\subsection{Rotational stiffness of the joints}

In the unstiffened direct-welded connection, the tube out-of-plane deformation is restrained at the corner of the column. The force transfer mechanism in the tube can be simplified by analyzing the horizontal plate strip as a one-way plate as shown in Fig. 24. The elastic rotational stiffness of the beam-to-column connection due to tube out-of-plane deformation, $k_{\theta}$, can be calculated with Eq. (4):

$k_{\theta}=\frac{2 E_{s} b_{e f f} t_{t}^{3} h_{b}^{2}}{L_{e}^{3}}$

where:

$E_{s}$ is the modulus of elasticity of steel material;

$b_{\text {eff }}$ is the average width of the flexible segment of the horizontal strip ( $=L_{e}$, assuming $45^{\circ}$ yield lines and thin flanges);

$t_{t}$ is the tube plate thickness;

$h_{b}$ is the distance between beam flange centres; and

$L_{e}$ is the clearance between beam flange tips to column edges.

The connection elastic rotational stiffness, which is estimated with Eq. (4), is indicated as the slope of the dotted line in Fig. 25. The beam end moment versus connection rotation curves which are obtained from the experiments and from FE analyses are also compared with the proposed equation. It is shown that the proposed equation can accurately estimate the elastic rotational stiffness of unstiffened direct-welded connections. 

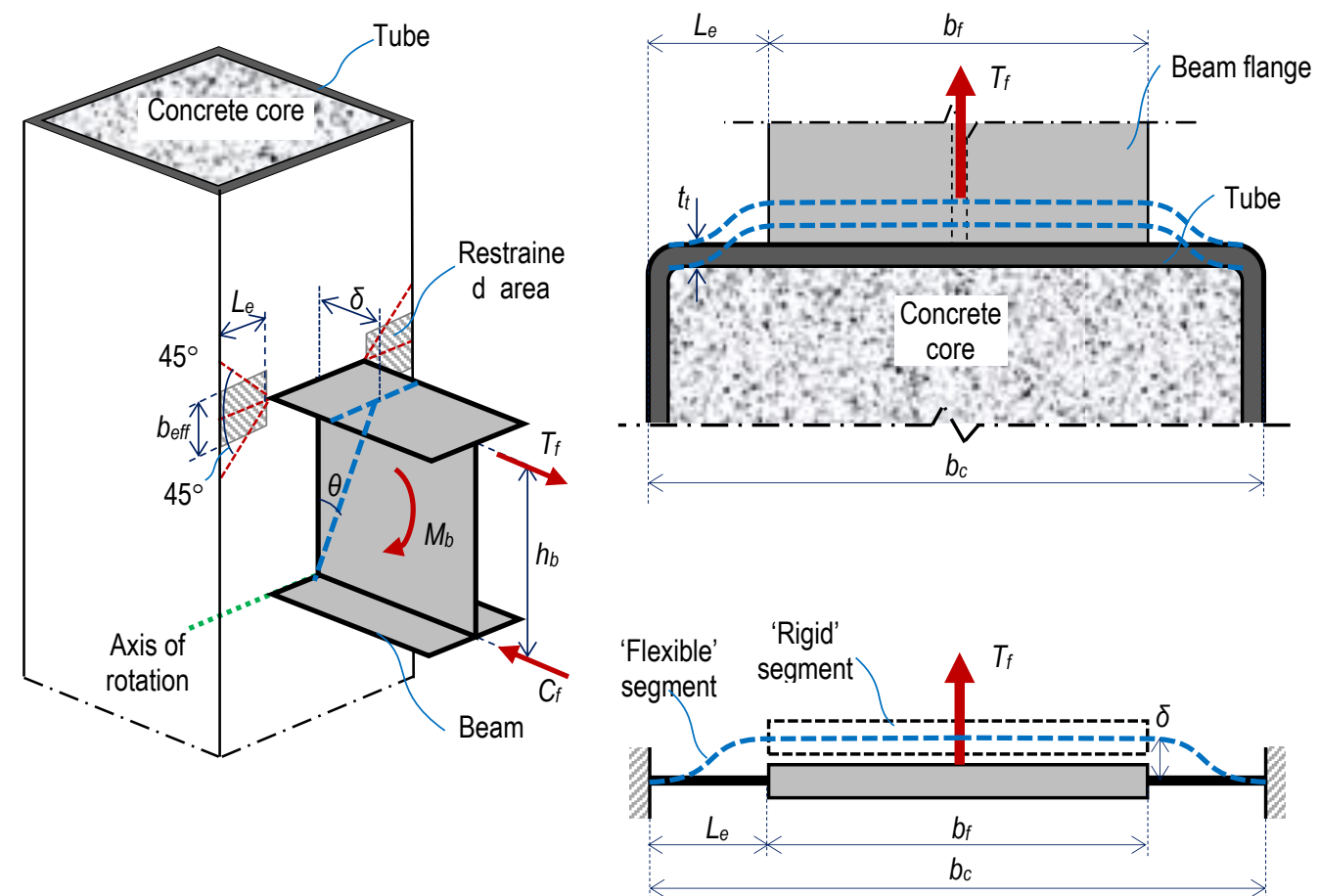

Fig. 24 One-way plate analogy for unstiffened direct-welded connection

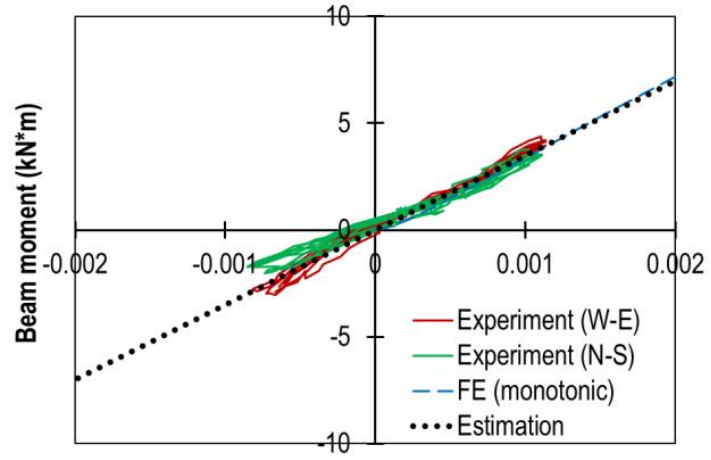

Rotation (rad)

Fig. 25 Beam moment versus rotation of unstiffened direct-welded connections

In the direct-welded connections with through-rods, both with and without washer plates, the stiffness of the tube plates and washer plates in vertical direction also contributes to the tube out-of-plane stiffness. However, the clamping effect of the rods is not continuously provided along the column width, as illustrated in Fig. 26. For connections stiffened with through-rods, the rotational stiffness, $k_{\theta}$, can be approximated using the following equation:

$k_{\theta}=\frac{2 E_{s} b_{e f f} t_{t}^{3} h_{b}^{2}}{L_{e}^{3}}+\beta_{r} \times \frac{2 E_{s} b_{c} t_{t}^{3} h_{b}^{2}}{s_{r}{ }^{3}}$

The fixity factor, $\beta_{r}$, is taken into account to consider the clamping effect of the rods (Fig. 27(a)).

For snug-tightened rods $\left(10 \% N_{t f}\right)$ :

$\beta_{r}=\min \left[1.1-3.2\left(\frac{t_{t}}{s_{r}}\right), 1.0\right]$

For proofloaded rods $\left(90 \% N_{t f}\right)$ :

$$
\beta_{r}=\min \left[1.6-4.5\left(\frac{t_{t}}{s_{r}}\right), 1.0\right]
$$

where:

$E_{S}$ is is the modulus of elasticity of steel material;

$b_{\text {eff }}$ is average width of the flexible segment of the horizontal strip (= $L_{e}$, assuming $45^{\circ}$ yield lines and thin flanges);

$t_{t}$ is the tube plate thickness;

$h_{b}$ is the distance between the beam flange centres;

$L_{e}$ is the clearance between the beam flange tips to the column edges;

$b_{c}$ is the column width; and

$s_{r}$ is the rod distance to the beam flange.

Similarly, for connections stiffened with through-rods and washer plates, the rotational stiffness, $k_{\theta}$, can be calculated with the following equation:

$k_{\theta}=\frac{2 E_{s} b_{e f f} t_{t}{ }^{3} h_{b}{ }^{2}}{L_{e}{ }^{3}}+\beta_{r w} \times \frac{2 E_{s} b_{w p}\left(t_{t}{ }^{3}+t_{w p}{ }^{3}\right) h_{b}{ }^{2}}{s_{r}{ }^{3}}$

The fixity factor, $\beta_{r w}$, is taken into account to consider the rods clamping effect (Fig. 27(b))

For snug-tightened rods $\left(10 \% N_{t f}\right)$ :

$\beta_{r w}=\min \left[0.05\left(\frac{t_{w p}}{s_{r}}\right)^{-1.6}, 1.0\right]$

For proofloaded rods $\left(90 \% N_{t f}\right)$ :

$\beta_{r w}=\min \left[0.07\left(\frac{t_{w p}}{s_{r}}\right)^{-1.6}, 1.0\right]$

where:

$t_{w p}$ is the washer plate thickness and

$b_{w p}$ is the outer washer plate width $\left(\geq b_{f}\right)$ 


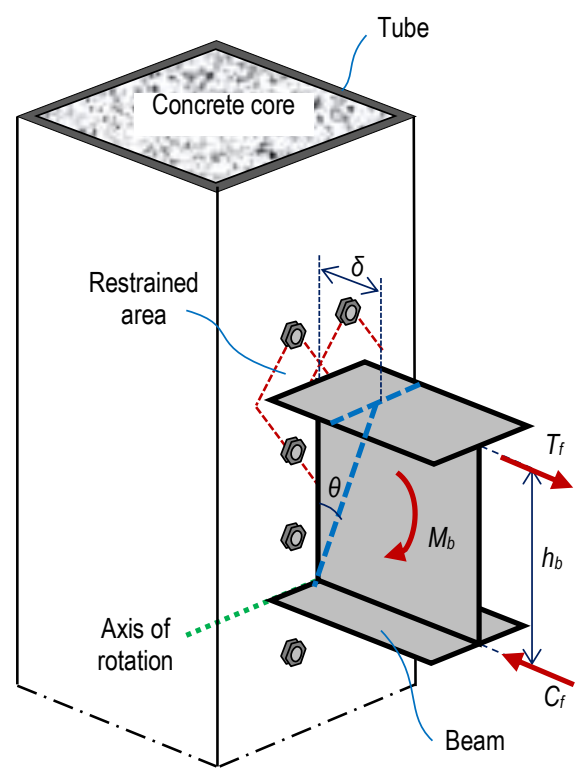

(a) With through-rods

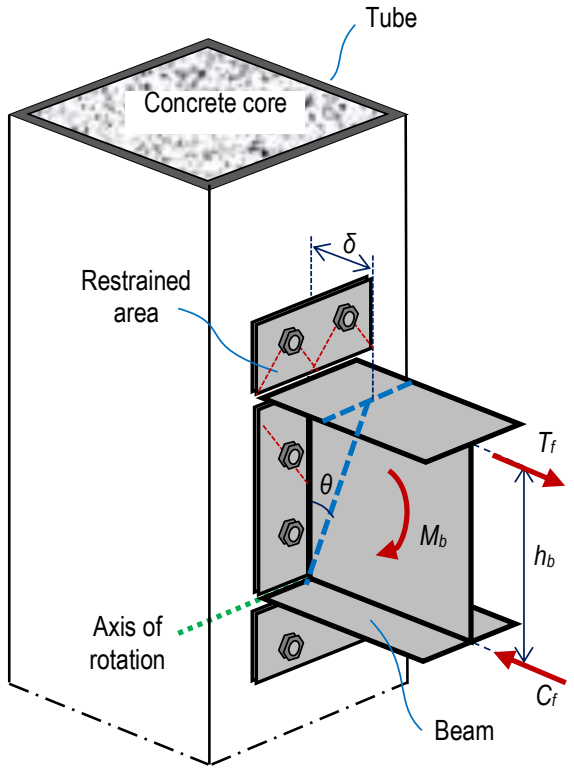

(b) With through-rods and washer plates

Fig. 26 Illustration of restrain provided by through-rods in improved direct-welded connections

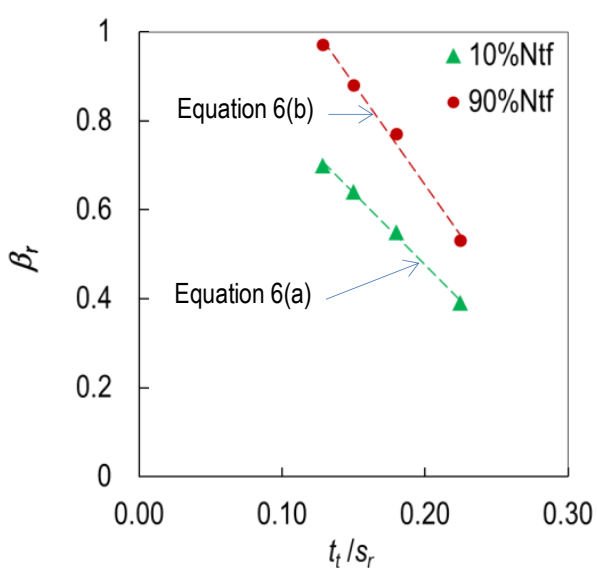

(a) With through-rods

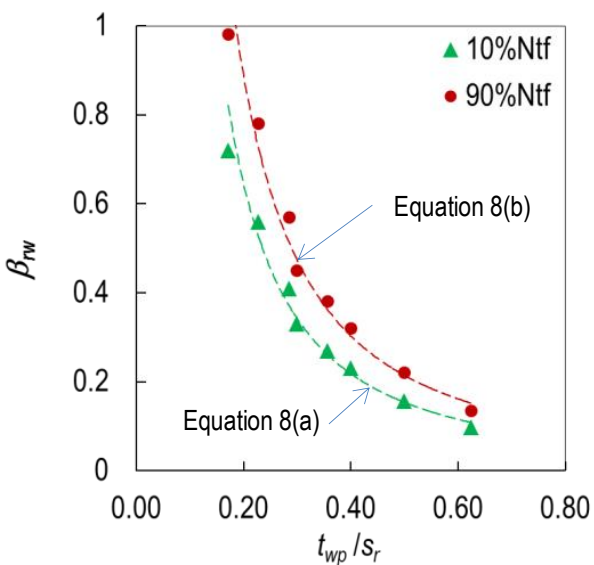

(b) With through-rods and washer plates

Fig. 27 Fixity factors for improved direct-welded connections

\section{Conclusions}

Bidirectional loading tests have been conducted on a CFST column subassembly with improved direct-welded beam-to-column connections. Finite element analyses were conducted to further evaluate the potential of the steel tube fracture which was observed during the tests. In addition, equations were developed to estimate the stress concentration from beam tension forces and the rotational stiffness of the connections. The following conclusions may be drawn from these tests, analyses, and equations:

1) The unstiffened direct-welded connections have low rotational stiffness due to flexibility of the tube plates in resisting out-of-plane deformations. Early yielding is likely to occur, which is indicated by the high stress increment rate at the tube.

2) The out-of-plane stiffness of the tube plates in joints with direct-welded connections can be improved by fastening and pretensioning threaded rods passing through the column. The stiffness can be further increased by

\section{References}

[1] AS/NZS 1252:1996. 1996. High-strength steel bolts with associated nuts and washers for structural engineering. Standards New Zealand.

[2] Chunhaviriyakul, P. G.A. MacRae, D. Anderson, G.C. Clifton, and R.T. Leon. 2015. "Suitability of CFT columns for New Zealand Moment Frames." Bulletin of the New Zealand Society for Earthquake Engineering 48 (1).

[3] Citipitioglu, A.M., R.M. Haj-Ali, and D.W. White. 2002. "Refined 3D finite element modeling of partially-restrained connections including slip." Journal of Constructional Steel Research 58: 995-1013. inserting thick washer plates underneath the nuts of the through-rods. The stiffness increases up to 2.4 times and 3.7 times that of the unstiffened connections in connections with through-rods only and with through-rods and washer plates, respectively.

3) The proposed improvement methods also reduce stress concentration in the column tube plates due to beam flange tension forces. The effectiveness of the methods is influenced by the configuration of the rods, their pretension forces, and the thickness of the washer plates. The effect of bidirectional loading on the behaviour of the connections is not significant.

4) Design formulations are developed to estimate the out-of-plane shear demand in the column tube plates. A stress concentration factor should be taken into account to consider the critical stress in the tube plates under beam flange tension forces. Formulations to estimate the elastic rotational stiffness of improved direct-welded connections are also proposed for moment frame analyses.
[4] Dutta, S.C., and S.K. Kunnath. 2013. "Effect of bidirectional interaction on seismic demand of structures." Soil Dynamics and Earthquake Engineering 52: 27-39.

[5] EN 1993-1-8. 2005. Design of steel structures, Part 1.8: Design of joints. Brussels: European Committee for Standardization.

[6] Hoang, V-L., J-P. Jaspart, and J-F. Demonceau. 2015. "Extended end-plate to concrete-filled rectangular column joint using long bolts." Journal of Constructional Steel Research 113: 156-168. 
[7] Kang, C.H., K.J. Shin, Y.S. Oh, and T.S. Moon. 2001. "Hysteresis behavior of CFT column to H-beam connections with external T-stiffeners and penetrated elements." Engineering Structures 23: 1194-1201.

[8] Li, L., W. Wang, Y. Chen, and L.H. Teh. 2017. "Column-wall failure mode of steel moment connection with inner diaphragm and catenary mechanism." Engineering Structures 131: 553-563

[9] Li, X., Y. Xiao, and Y.T. Wu. 2009. "Seismic behavior of exterior connections with steel beams bolted to CFT columns." Journal of Constructional Steel Research 65: 1438-1446.

[10] MacRae, G.A., and H.T. Tagawa. 2001. "Seismic Behavior of 3D Steel Moment Frame with Biaxial Columns.” Journal of Structural Engineering 127 (5): 490-497.

[11] Nishiyama, I., T. Fujimoto, T. Fukumoto, and K. Yoshioka. 2004. "Inelastic forcedeformation response of joint shear panels in beam-column moment connections to concrete-filled tubes." Journal of Structural Engineering 130: 244-252.

[12] Park, T., W-S. Hwang, R. T. Leon, and J. W. Hu. 2011. "Damage Evaluation of Composite-Special Moment Frames with Concrete-filled Tube Columns under Strong Seismic Loads.” KSCE Journal of Civil Engineering 15 (8): 1381-1394.

[13] Schneider, S.P., and Y.M. Alostaz. 1998. "Experimental behavior of connections to concrete-filled steel tubes.” Journal of Constructional Steel Research 45 (3): 321-352.
[14] Sheet, I.S., U. Gunasekaran, and G.A. MacRae. 2013. "Experimental investigation of CFT column to steel beam connections under cyclic loading." Journal of Constructional Steel Research 86: 167-182.

[15] SIMULIA. 2012. Abaqus/CAE User's Manual.

[16] Tjahjato, H., G. MacRae, A. Abu, C. Clifton, T. Beetham, and N. Mago. 2019 "Diaphragm Axial Capacity for External Diaphragm Connections (EDCS) in Square CFST Column Structures." Bulletin of the New Zealand Society for Earthquake Engineering 52 (3)

[17] Wang, J-F., L-H. Han, and B. Uy. 2009. "Behaviour of flush end plate joints to concrete-filled steel tubular columns." Journal of Constructional Steel Research 65: 925-939.

[18] Xu, M., S. Gao, S. Zhang, and H. Li. 2018. "Experimental study on bolted CFSTcolumn joints with different configurations in accommodating column-loss." Journal of Constructional Steel Research 151: 122-131.

[19] Yao, H., H. Goldsworthy, and E. Gad. 2008. "Experimental and Numerical Investigation of the Tensile Behavior of Blind-Bolted T-Stub Connections to Concrete-Filled Circular Columns." Journal of Structural Engineering 134: 198-208. 